\title{
30. Durch Arthropoden übertragene (Arbo)-Viruskrankheiten
}

Die Arboviren (durch Arthropoden übertragene Viren $=$ arthropode - borne viruses) sind eine, nach ihrer Funktion zusammengefaßte Gruppe von Infektionserregern, die zwischen empfänglichen Wirbeltieren durch den Biß blutsaugender Arthropoden übertragen werden. Diese Viren können sich in den Organen des empfänglichen Arthropoden vermehren, ohne in diesem Wirt offensichtliche Krankheitssymptome oder Gewebeschäden hervorzurufen. Der Cyclus Wirbeltier $\rightarrow$ Arthropode $\rightarrow$ Wirbeltier wird in der Natur durch diesen Vektor aufrechterhalten, der durch die Aufnahme von Blut eines Wirbeltieres während der virämischen Phase lebenslänglich infektiös wird.

Die Bezeichnungen der einzelnen Viren wurden ursprünglich von den durch sie hervorgerufenen Erkrankungen abgeleitet, da die Erkennung des Krankheitsbildes meist vor der Isolierung des Infektionserregers erfolgte (Gelbfieber, Dengue, Pferdeencephalitiden). Später bevorzugte man zur Bezeichnung der Viren eine Kombination aus der geographischen Region, in der die Virusisolierung gelang, mit dem Krankheitsbild (St. Louis-Encephalitis, ColoradoZeckenfieber, ,west Nile fever", russische Frühsommer-Meningoencephalitis). In letzter Zeit einigte man sich auf Bezeichnungen neu isolierter Viren nach dem geographischen Gebiet, in dem die Virusisolierung erfolgte (Hart Park, Kern Canyon, Cache Valley).

Obwohl man Arboviren in allen tropischen und suptropischen Gebieten des Festlandes und auch auf einigen Inseln findet, sind sie vor allem in den tropischen Regenwäldern der Erde verbreitet. Diese Verbreitung ist im Hinblick auf die günstigen klimatischen Bedingungen, die Vielzahl der dort lebenden Tiere der verschiedensten Arten und der Insekten verständlich. Da die Arboviren durch einen Lebenscyclus erhalten werden, bei dem sowohl Arthropoden als auch Wirbeltiere beteiligt sind, zeigen die Tropen die günstigsten Bedingungen für die Aufrechterhaltung dieses biologischen Cyclus.

Zumindest 350 verschiedene Viren werden gegenwärtig zu den Arboviren gerechnet, die entsprechend ihrer Antigenverwandschaft in mehrere Untergruppen eingeteilt werden, deren Mitglieder in einem unterschiedlichen Ausmaß gemeinsame, durch die Komplementbindungsreaktion (KBR), den Hämagglutinationshemmungstest (HHT) und - weniger häufig durch den Neutralisationstest (NT) nachweisbare Antigene besitzen. Diese Viren können in sieben Hauptgruppen unterteilt werden (jeweils 10 oder mehr Mitglieder pro Gruppe), weitere werden in 18 kleinen Gruppen zusammengefaßt ( 2 bis 7 Mitglieder pro Gruppe); viele können keiner dieser Gruppen zugeteilt werden.

Die Arboviren werden gegenwärtig nach ihren biochemischen und biophysikalischen Eigenschaften eingeordnet. Deshalb findet man jetzt Arboviren in den Familien Togaviridae, Bunyaviridae, Reoviridae, Arenaviridae und Rhabdoviridae (s. Tabelle 30-1).

Alle entsprechend untersuchten Viren besitzen RNS als Genom, die meisten Arboviren werden durch Lipidlösungsmittel (Äther oder Natriumdesoxycholat) inaktiviert. Eine Ausnahme hiervon machen Nodamura-Virus (als Picornavirus eingruppiert) und die durch Arthropoden übertragenen Orbiviren, zu denen das ,bluetongue"-Virus, das Virus der afrikanischen Pferdekrankheit und noch weitere gehören (s. Kapitel 39). Nodamura-Virus ist ein virulentes Insekten-Virus, das - entgegen der allgemeinen Meinung über die Pathogenität der Insektenviren - sich in Säugern vermehren kann und sie hierbei auch tötet.

Obwohl eine Einteilung vieler Arboviren nach ihren biochemischen und biophysikalischen Eigenschaften jetzt möglich ist, werden diese Erreger für medizinische Übrlegungen nach ihrer serologischen Verwandtschaft gruppiert:

1. Gruppe A (Genus Alphavirus) und Gruppe B (Genus Flavivirus) gehören zur Familie Togaviridae, deren Genom als Einzelstrang-RNS mit einem Molekulargewicht von $3 \times 10^{6}$ vorliegt. Die Viruspartikel sind sphärisch und besitzen eine Lipid-haltige, Äther-empfindliche Hüllmembran. Die Viren vermehren sich im 
Tabelle 30-1. Gegenwärtig gültige Taxonomie einiger Arboviren

\begin{tabular}{ll}
\hline Klassifizierung & Mitglieder dieser Gruppe \\
\hline $\begin{array}{l}\text { Togaviridae } \\
\text { Genus Alphavirus }\end{array}$ & Gruppe A: Aura, Chikungunya, östliche Pferdeencephalitis (EEE), Getah, \\
& Mayaro, Middleburg, Mucambo, Ndumu, O'Nyong-nyong, Pixuna, Ross \\
& River, Semliki Forest, Sindbis, Una, Venezuela und westliche Pferdeencepha- \\
& litis (WEE), Whataroa \\
& Gruppe B: Bussuquara, Dengue, Ilheus, Israel-Truthahn-Meningoencephali- \\
& tis, japanische B-Encephalitis, Kunjin, Kyasanur Forest Disease, Langat, \\
& Louping ill, Modoc, Murray-Valley-Encephalitis, Ntaya, Omsk-hämorrhagi- \\
sches Fieber, Powassan, Spondweni, St. Louis-Encephalitis (SLE), Zecken- & Encephalitis, Uganda S, US-Fledermaus-Speicheldrüsenvirus, Wesselsbron, \\
& West Nile Fever, Gelbfieber, Zika
\end{tabular}

Bunyaviridae

Genus Bunyavirus Bunyamvera (18 Mitglieder)-, Bwamba (2)-, C (11)-, California (11)-, Capim (6)-, Guama (6)-, Koongol (2)-, Patois (4)-, Simbu (16)-, Tete (4)-Gruppen; 7 nicht zugeordnete Viren

Fragliche Mitglieder UuKuniemi (7 Mitglieder)-, Anopheles A (3)-, Anopheles B (2)-, Bakau (2)-, Krim-Kongo-hämorrhagisches Fieber (2)-, Kaisodi (3)-, Mapputta (3)-, Nairobi-Schafkrankheit (3)-, Phlebotomus-Fieber (20)-, Turlock (3)Gruppen; 8 nicht zugeordnete Viren

Reoviridae Genus Orbivirus

Afrikanische Pferdekrankheit, ,,bluetongue“, Colorado-Zeckenfieber

Rhabdoviridae

Genus Vesiculovirus Cocal, Hart Park, Kern Canyon, vesiculäre Stomatitis

Arenaviridae

Genus Arenavirus Junin, Lassa, Machupo, Pichinde

Picornaviridae

Genus Enterovirus Nodamura

Cytoplasma, ihre Reifung erfolgt durch Sprossung an der Zellwand. Die Viren der Gruppe A sind deutlich größer $(40-80 \mathrm{~nm})$, sie werden durch Sulfhydrylreagenzien nicht inaktiviert und sind auch gegen Proteasen (Trypsin) resistent, während die Viren der Gruppe B gegen Proteasen empfindlich sind. Alle Viren der Gruppe A vermehren sich in den als Vektor dienenden Arthopoden; diese Fähigkeit konnte dagegen nicht für alle Viren der Gruppe B, die jedoch serologisch miteinander verwandt sind, bewiesen werden. Am eingehendsten untersucht wurden die Pferdeencephalitis-Viren (westliche, östliche und Venezuela-Pferdeencephalitis), ferner Sindbis- und Semliki-Forest-Virus. Das in Afrika und Indien vorkommende Sindbisvirus (Alphavirus sindbis) wurde zur Prototyp-Species gewählt. Diese Viren sind vor allem als Ursache uncharakteristischer fieberhafter
(,,Dengue-ähnlicher") Erkrankungen und als Ursache von Encephalitiden von Belang.

2. Gruppe B (Genus Flavivirus): Das Gelbfiebervirus (Flavivirus febricus) wurde als Prototyp-Species gewählt. Zahlreiche Viren dieser Gruppe können entsprechend der Antigenstruktur in vier Untergruppen eng verwandter Erreger unterteilt werden: a) Virus der japanischen B-Encephalitis, Virus der St. Louis-Encephalitis, Virus der Murray Valley-Encephalitis, West Nile-Fieber, Ilheus-Virus, Kunjin-Virus; b) Dengue-Viren; c) Gelbfieber-Virus, Uganda-S-Virus, Zika-Virus; d) Gruppe der Zeckenbißfieber. In dieser zuletzt genannten Untergruppe sind Viren zusammengefaßt, die hämorrhagische Fieber (hämorrhagisches Fieber von Omsk, Kyasanur-Waldkrankheit) oder Encephalitiden (russische Frühsommer-Meningo- 
encephalitis, biphasische Meningoencephalitis, Powassan) hervorrufen können.

3. Die Bunyamwera-Hauptgruppe besteht aus 10 Gruppen und umfaßt 88 verschiedene Virusarten. Diese Hauptgruppe wurde ursprünglich geschaffen, um geringe serologische Kreuzreaktionen zwischen einzelnen Mitgliedern der Gruppen zu berücksichtigen. Bei diesen Kreuzreaktionen zwischen den verschiedenen Gruppen sind im allgemeinen nur wenige Viren beteiligt und sie sind häufig nur durch eine kreuzweise durchgeführte KBR an der Grenze der Empfindlichkeit dieses Testverfahrens nachweisbar. Alle Viren dieser Gruppen sind morphologisch nicht voneinander unterscheidbar. Aus diesen Gründen wurden sie in der Familie Bunyaviridae, Genus Bunyavirus, zusammengefaßt.

Bunyaviren enthalten Einzelstrang-RNS als Genom, die wahrscheinlich segmentiert ist; ihr Molekulargewicht beträgt $6,8 \times 10^{6}$. Das Virion ist sphärisch, der Durchmesser des umhüllten Partikels beträgt $90-100 \mathrm{~nm}$. Die Hülle besteht aus einer $5 \mathrm{~nm}$ dicken Membran, die mit 8-10 nm langen Vorstülpungen bedeckt ist. Die Hülle ist aus 2 verschiedenen Glykopeptidarten zusammengesetzt, die zu Hohlzylindern zusammengebaut sind (Durchmesser 10-12 nm, Durchmesser des inneren Hohlraums $5 \mathrm{~nm}$ ). Diese morphologischen Bausteine sind in einem Ikosaeder-Muster zur Virusoberfläche zusammengebaut. Die Membran, an der diese Oberflächen-Bauelemente haften, besteht wahrscheinlich aus einer Lipid-Doppelschicht. Unmittelbar unter dieser Membran liegt offenbar das strangartige Nucleoproteid. Bunyaviren werden im Cytoplasma synthetisiert und reifen durch Sprossung in intracelluläre (Golgi-)Vesikel.

Alle Viren der Bunyamwera-Hauptgruppe vermehren sich in dem, als Vektor dienenden Arthropoden; sie konnten aus Mücken in verschiedenen Teilen der Welt (Afrika, Südamerika, Indien, Malaysia, Trinidad, USA) isoliert werden. Die wesentlichen Erreger von Krankheiten beim Menschen unter den Bunyaviren gehören zu den Bunyamwera-, C- und California-Gruppen. Zahlreiche Viren der Bunyamwera-Gruppe verursachen uncharakteristische fieberhafte Erkrankungen des Menschen, während die Erreger der C-Gruppe häufiger die Ursache akuter fieberhafter Erkrankungen mit Kopfschmerzen und einem allgemeinen Krankheits- gefühl sind. Viren der California-Gruppe verursachen eine Meningoencephalitis; 8 Viren dieser Gruppe wurden innerhalb der USA isoliert (siehe Bunyavirus-Encephalitis).

4. Eine weitere große Gruppe von Arboviren, die den Viren der Bunyamwera-Hauptgruppe ähnlich, in ihrer Antigenität jedoch unterschiedlich hiervon sind, besteht aus 10 Gruppen mit über 56 verschiedenen Virusarten. Sie werden z.Z. als ,,mögliche Mitglieder" des Genus Bunyavirus angesehen, müssen aber — sobald mehr Informationen über sie vorliegen - als gesondertes Taxon zusammengefaßt werden. Der Prototyp dieser Gruppe ist das UukuniemiVirus; hier werden zahlreiche bedeutende Krankheitserreger von Mensch und von verschiedenen Haustieren zusammengefaßt. Besonders bedeutend sind die Erreger des Krimhämorrhagischen Fiebers und des Kongo-hämorrhagischen Fiebers beim Menschen sowie der Nairobi- und der Rift Valley-Erkrankung bei Schafen. 5 Mitglieder der Phlebotomus(sog. Sandfliege-)Fieber-Gruppe (Neapel, Sizilien, Punta Toro, Chagres, Candiru) verursachen beim Menschen ein uncharakteristisches fieberhaftes Krankheitsbild (Pappatacifieber). Als Vektor der meisten Viren der PhlebotomusGruppe dienen die Weibchen von Phlebotomus papatasii; 2 Arten konnten jedoch bisher ausschließlich von Stechmücken isoliert werden, so daß zu dieser Gruppe offenbar sowohl durch Phlebotomus- als auch durch Stechmücken übertragene Viren gehören.

5. Zu den Arboviren, die gegenwärtig als Familie Reoviridae, Genus Orbivirus, klassifiziert werden, gehören die Erreger des ,,bluetongue“", der afrikanischen Pferdekrankheit und des Colorado-Zeckenfiebers (s. Kapitel 39). Die afrikanische Pferdekrankheit hat sich von dem enzootischen Gebiet in Afrika über das östliche Mittelmeer nach Pakistan und Indien ausgebreitet, wo sie allein im Jahr 1960 über 50000 Todesfälle unter den Pferden verursachte. Über eine Pathogenität dieses Virus für Menschen ist bisher nichts bekannt.

Chenuda- und zahlreiche weitere, durch Zekken übertragene Viren der Kemerovo-Gruppe ähneln den Orbiviren und werden deshalb vielleicht zu diesem Genus gezählt werden, sobald mehr Informationen vorliegen. Die Viren der Kemerovo-Gruppe wurden aus Zecken in Osteuropa, Ägypten und im Sudan isoliert; bei einigen Isolierungen bestand ein gewisser $\mathrm{Zu}$ - 
sammenhang mit gutartigen Encephalitis-Erkrankungen bei Menschen. Diese Viren können auch Pferde, Rinder, Vögel und kleine Säugetiere infizieren.

6. Zu den Arboviren, die in die Familie Arenaviridae, Genus Arenavirus, eingruppiert werden, gehören das Junin-Virus (argentinisches hämorrhagisches Fieber) und das Machupo-Virus (bolivianisches hämorrhagisches Fieber). Diese beiden Erreger sind Teil des Tacaribe-Komplexes serologisch verwandter Arboviren, zu dem auch Amapari-, Pichinde-, Parane-, Tamiami(isoliert in den Sumpfgebieten Floridas), Latino- und Tacaribe- (isoliert von Fledermäusen auf Trinidad) Viren gehören. Moskitos als Vektoren wurden nicht bei allen Viren des Tacaribe-Komplexes nachgewiesen, bei einigen wurden Milben als Überträger vermutet, der Beweis hierfür steht jedoch aus. Wirtstiere der meisten Viren dieser Gruppe sind Nagetiere, eine Übertragung auf andere Säugetiere und auf den Menschen ist selten. Auch das Lassa-Virus, Ursache einer schweren fieberhaften Erkrankung mit hoher Letalität bei Menschen, ist ein Arenavirus.

7. In der Familie Rhabdoviridae, Genus Vesiculovirus, werden Cocal-, Hart Park-, Kern Canyon-Virus sowie das Virus der vesiculären Stomatitis (s. Kapitel 33) zusammengefaßt.

8. Das einzige Arbovirus, das zur Familie Picornaviridae gehört, ist das Nodamura-Virus. Dieser Erreger ist ein virulentes Insektenvirus, das - im Gegensatz zur allgemeinen Ansicht über die Pathogenität von Insektenviren - sich in Säugetieren vermehren und sie auch töten kann.

\section{Infektionen des Menschen}

Etwa 75 verschiedene Arboviren können den Menschen infizieren, doch sind nur etwa $60 \%$ hiervon in der Lage, ein manifestes Krankheitsbild beim Menschen auszulösen. Alle den Menschen infizierenden Arboviren sind die Ursache von Zoonosen und der Mensch ist nur ein zufälliger Wirt des Virus, der zum Aufrechterhalten des Infektionscyclus keine Bedeutung hat; als Ausnahmen von dieser Verallgemeinerung können nur das Städte-Gelbfieber und das Denguefieber angesehen werden. Einige Infektionscyclen sind sehr einfach und werden durch ein Wirbeltier (Säuger oder Vogel) und eine Stechmückenart oder eine Zecke aufrechterhal- ten (Dschungel-Gelbfieber, Pferdeencephalitisviren, Virus der japanischen B-Encephalitis und der St. Louis-Encephalitis, Colorado-Zeckenfieber). Dagegen können andere Infektionscyclen sehr komplex sein. So treten z. B. viele Fälle der zentraleuropäischen biphasischen Meningoencephalitis nach dem Genuß roher Milch von infizierten Ziegen und Kühen auf. Diese Tiere werden beim Grasen auf Zecken-befallenen Weiden infiziert, auf denen ein Zecken-Nagetier-Infektionscyclus abläuft.

Die durch Arboviren hervorgerufenen Erkrankungen können in drei klinische Syndrome unterteilt werden: 1 . uncharakteristische fieberhafte Erkrankung, die häufig als ,,Dengue-ähnlich" bezeichnet wird und die mit oder ohne ein Exanthem ablaufen kann und deren Verlauf meist gutartig ist; 2 . Encephalitis, die häufig mit hoher Letalität einhergeht; 3. hämorrhagische Fieber, die ebenfalls häufig schwer verlaufen und mit hoher Letalität einhergehen. Diese Unterteilung ist etwas willkürlich, und einige Arboviren sind die Ursache von mehr als einem Syndrom (z. B. Dengue).

Das Ausmaß der Virusvermehrung im Organismus und der bevorzugte Befall von Geweben oder Organen bestimmt die klinische Symptomatik. So können einzelne Arbovirusarten eine gutartige fieberhafte Erkrankung bei einigen Erkrankten hervorrufen, in anderen dagegen eine Encephalitis oder eine hämorrhagische Diathese. Bei epidemischen Häufungen einzelner Infektionen wird jedoch eines der angegebenen Syndrome vorherrschen, so daß eine vorläufige Diagnose gestellt werden kann. Die endgültige Diagnose beruht jedoch auf weiteren epidemiologischen Erhebungen und serologischen Befunden.

Das Initialstadium einer Arbovirusinfektion verläuft asymptomatisch und entspricht der ,inneren“ Inkubationszeit der Virusvermehrung. Danach treten - in Zusammenhang mit der Virusausbreitung - die klinischen Manifestationen abrupt auf. Als übliche klinische Symptome können Kopfschmerzen, ein allgemeines Krankheitsgefühl, Schwindelgefühl, Erbrechen, Muskelschmerzen und vor allem Fieber gelten, das stets - und häufig als einziges Symptom vorhanden ist. Die Erkrankung kann in diesem Stadium abbrechen, mit oder ohne Exanthem wieder auftreten oder auch anschließend hämorrhagische Manifestationen aufweisen, die als Folge von Gefäßschäden beobachtet werden. Nicht selten verläuft die Periode der Virämie 
asymptomatisch und nach einem Virusbefall des Zentralnervensystems kommt es zum akuten Beginn der Encephalitis.

Die angegebenen klinischen Kategorien werden in den folgenden Abschnitten verwendet, in denen einige wesentliche Arbovirus-Erkrankungen besprochen werden.

\section{Togavirus-Encephalitis (SLE, EEE, WEE)}

Encephalitiden können durch eine Vielzahl neurotroper Viren hervorgerufen werden. Diese Erreger führen zu einer Infektion, häufig in Epidemien, bei denen die klinischen Symptome Ausdruck des Befalls von Gehirn und Rückenmark sind. Derartige Erkrankungen mit gleichartiger Epidemiologie hat man als ,,durch Arthropoden übertragene Encephalitiden"zusammengefaßt. Obwohl diese Erkrankungen viele Gemeinsamkeiten aufweisen, ist ihre geographische Verbreitung häufig äußerst unterschiedlich (Tabelle 30-1). Die charakteristische geographische Verteilung der Arboviren ist Folge der ökologischen Verteilung der typischen Viruswirte und der Vektoren der Erreger. So tritt die westliche Pferdeencephalitis (WEE) vor allem in den westlichen Teilen der USA und in Kanada auf, die östliche Pferdeencephalitis (EEE) findet sich dagegen in den östlichen und südlichen Teilen der USA. Die Venezuela-Pferdeencephalitis (VEE) beobachtet man in Süd- und Mittelamerika und in den Südstaaten der USA, die St. Louis-Encephalitis (SLE) in den mittleren und westlichen Teilen der USA (ihre Ausbreitung schwankt jedoch von Jahr zu Jahr), die japanische B-Encephalitis (Encephalitis japonica B, JBE) im Fernen Osten (Japan, Korea, China, Malaysia, Indien) und die Murray Valley-Encephalitis (MVE) in Australien. Alle bisher genannten Arboviren gehören zur Familie Togaviridae. Eine andere Gruppe von Arboviren als Ursache von Encephalitiden, die California-Gruppe (Familie Bunyaviridae), wird später in einem besonderen Abschnitt besprochen.

Einer der Gründe für das auffällige Fehlen von Epidemien virusbedingter Encephalitiden im Mittleren Osten kann das Vorherrschen des West Nile-Virus in diesen Gebieten sein. Dieses Virus ist der Erreger einer leichten, kurzdauernden Erkrankung des Menschen; es gehört zum gleichen Genus (Flavivirus) wie JBE, SLE und MVE, mit denen es gemeinsame Antigenkom- ponenten besitzt. Die weite Verbreitung von West Nile-Fieber im Mittleren Osten hat vielleicht zu einer Steigerung der Resistenz in der Bevölkerung gegen jene Encephalitiden geführt, die durch verwandte Viren hervorgerufen werden.

Bei Personen, die früher einmal mit DengueVirus infiziert worden waren und Antikörper gegen Dengue-Virus besitzen, besteht ein partieller Schutz gegen Infektionen mit SLE-Virus.

Die meisten Arboviren bewirken bei saugenden Mäusen eine Encephalitis, während dies nur wenige beim Menschen herbeiführen. Beim West Nile-Virus, dem Gelbfiebervirus oder bei den Dengueviren können individuelle Empfänglichkeit, Immunstatus des Patienten, das Auftreten von Virusmutanten oder die übertragene Virusdosis für das gelegentliche Auftreten von Encephalitiden verantwortlich sein.

Eine Encephalitis (oder Meningoencephalitis) kann ebenfalls als Komplikation bei einer Reihe anderer Erkrankungen (Masern, Mumps, infektiöse Hepatitis, Pocken, Windpocken, Zoster u.a.) auftreten. Häufig tritt in diesen Fällen eine Überempfindlichkeit vom verzögerten Typ auf; aus diesem Grunde werden die Erkrankungen häufig als ,,postinfektiöse“ Encephalitiden bezeichnet.

\section{Eigenschaften der Togaviren}

\section{A. Nucleinsäure: RNS.}

B. Größe: Die Arboviren der Gruppen A und B sind klein, der Partikeldurchmesser beträgt zwischen 20 und $80 \mathrm{~nm}$. Einige dieser Viren hat man gereinigt und fand, daß sie Phospholipide, Fettsäuren und Cholesterin außer dem Nucleoprotein enthielten.

C. Verhalten gegenuiber physikalischen und chemischen Einfliissen: Neu isolierte Viren sind bei Zimmertemperatur instabil. Sie können durch Einfrieren bei $-70^{\circ} \mathrm{C}$, vor allem nach Zusatz von $25 \%$ Kaninchenserum oder $4 \%$ Rinderserumalbumin, aufbewahrt werden. Arboviren werden durch Äther, Galle oder durch Natriumdesoxycholat $(1: 1000)$ inaktiviert. Hierdurch können neu isolierte Viren ohne Schwierigkeit von den Enteroviren unterschieden werden, die gegenüber Desoxycholat resistent sind.

D. Empfänglichkeit verschiedener Tierarten und Vermehrung der Viren: Diese Viren sind für eine Vielzahl von Tieren infektiös; die Viren 
der östlichen, westlichen und Venezuela-Pferdeencephalitis sind für eine große Zahl jährlich auftretender Erkrankungen und Todesfälle bei Pferden und Eseln verantwortlich. Das meist verwendete Laboratoriumstier ist die Maus, die am einfachsten durch eine intracerebrale Inoculation infiziert werden kann. Vor allem sind junge Mäuse für eine Infektion durch diese Viren empfänglich. Im empfänglichen Wirbeltier tritt die primäre Virusvermehrung entweder im Knochenmark oder im lymphatischen Gewebe sowie im Gefäßendothel auf. Eine Virusvermehrung im Zentralnervensystem scheint von der Fähigkeit des Virus, die Blut-Hirnschranke zu passieren und Nervenzellen zu infizieren, abzuhängen. Bei Hühnern, Tauben, Enten, Fledermäusen, Meerschweinchen, Kaninchen und Affen kann man durch parenterale Verimpfung kleiner Virusmengen eine inapparent ablaufende Infektion erzeugen, während der das Virus mehrere Tage lang im Blut kreist. In der Natur ist diese Art der Infektion als Quelle des Virus für die Insekten, die als Vektor der Erkrankung dienen, anzusehen.

Nach Inoculation in den Dottersack oder die Chorioallantois vermehren sich diese Viren auch in embryonierten Hühnereiern. Ferner können sie ohne Schwierigkeiten in Gewebekulturen aus Mäuse-, Enten- oder Hühnerembryonen oder in Zellinien aus Säugetierzellen vermehrt werden. Außerdem haben Zellstämme aus Zellen von Aedes albopictus und A. aegypti eine selektive Empfänglichkeit für Viren, die durch Stechmücken übertragen werden, vor allem Arboviren der Gruppe B.

Alle Togaviren vermehren sich im Cytoplasma. Das Virusgenom (RNS) wird aus dem Partikel freigesetzt und wirkt an Polyribosomen als mRNS, um die Synthese der großen, als Vorstufe dienenden Polypeptide zu dirigieren; diese Polypeptide werden anschließend gespalten und bilden die Struktur-Polypeptide des Virus. Die RNS dient ebenfalls als Matrize der neu zu bildenden RNS; hierbei werden replikative Intermediärformen gebildet. Der Vermehrungscyclus gleicht in dieser Hinsicht der Vermehrung der Picornaviren. Die Togaviren besitzen jedoch 2 oder noch mehr Struktur-Polypeptide, die eine Glykolysierung und anschließende Spaltung durchlaufen und in die Cytoplasmamembran der Wirtszelle eingebaut werden. Die Viruspartikel erhalten durch Sprossungsvorgänge an den derart veränderten Bezirken der Membran ihre Hülle sowie die glykolysierten
Polypeptide. Im Nucleocapsid der Togaviren kann nur ein Polypeptid nachgewiesen werden, während es im Nucleocapsid der Picornaviren 4 sind.

Die Virusvermehrung kann durch die direkte Beobachtung der cytopathischen Veränderungen und durch Anwendung der virusspezifischen Immunfluorescenz, ferner durch die Bildung von Virushämagglutinin, das direkt in der Gewebekultur durch den Hämadsorptionstest nachgewiesen wird, verfolgt werden. Durch Verwendung der Plaquetechnik hat man reproduzierbare und empfindliche Tests mit den Viren der Gruppe A und B in Gewebekulturen von Hühnerembryonen bzw. Entennierenzellen, BHK-Zellen oder Vero-Zellen entwickelt. Arboviren zeigen eine homotype und heterotype Interferenz sowie eine Beeinflußbarkeit durch Interferon.

E. Antigeneigenschaften: Es lassen sich komplementbindende Antigene und Hämagglutinine präparieren, wobei als Ausgangsmaterial im allgemeinen das Hirn infizierter saugender Mäuse wegen seines geringen Fettgehaltes verwendet wird. Die Hämagglutinine dieser Viren sind Teile des infektiösen Viruspartikels. Die Bindung zwischen Hämagglutinin und Erythrocyt ist irreversibel. Der Erythrocyt-Virus-Komplex ist noch infektiös, kann aber durch den Zusatz von Antiseren neutralisiert werden, was zur Ausbildung von großen Gitterstrukturen führt.

Einige dieser Viren weisen eine überlappende Antigenität auf, die am einfachsten durch eine Kreuzreaktion mit dem Hämagglutinationshemmungstest aufgezeigt werden kann. Diese Überlappung beruht auf der Gegenwart von einem oder auch von mehreren kreuzreagierenden Antigenen, die außer den stamm-spezifischen Antigenen vorhanden sind. Aus diesem Grund besitzen Immunseren, die gegen einen Stamm gerichtet sind, sowohl stamm-als auch gruppenspezifische Antikörper.

Durch Absorption der Immunseren mit heterologen Viren der gleichen Gruppe kann man weitgehend spezifische Seren erhalten. Diese Antiseren reagieren im Hämagglutinationshemmungstest nur noch mit dem homologen, dagegen nicht mehr mit dem heterologen Stamm. Durch Verwendung derartiger absorbierter Seren wurde die Analyse der komplexen Antigenstruktur einiger Arboviren innerhalb der großen Gruppe sowie die Identifizierung neu isolierter Stämme möglich. 


\section{Pathogenese und Pathologie}

Die Pathogenese der menschlichen Erkrankung ist nur unzureichend untersucht, aber in einigen Fällen kann die Erkrankung des experimentell infizierten Tieres als Modell für die menschliche Erkrankung herangezogen werden. So zeigt sich, daß z.B. die Pferdeencephalitiden beim Pferd biphasisch verlaufen. In der ersten Krankheitsphase (,minor illness") vermehrt sich das Virus in den nicht-neuralen Geweben und ist drei Tage vor den ersten Anzeichen einer ZNS-Beteiligung im Blut nachweisbar. In der zweiten Phase (,major illness") vermehrt sich das Virus im Gehirn, hierbei werden Zellen geschädigt, zerstört und die Encephalitis wird klinisch apparent. Diese zwei Phasen können streng unterschieden sein oder sich gegenseitig überlappen. Es konnte bisher nicht geklärt werden, ob beim Menschen eine primäre Virusvermehrung im nicht-neuralen Gewebe stattfindet mit einer sekundären Freisetzung des Virus in den Blutstrom, bevor es das ZNS erreicht. Bei experimentell infizierten Affen konnte dagegen eine Virusvermehrung in nicht-neuralem Gewebe nachgewiesen werden.

Bevor die klinische Erkrankung manifest wird, müssen bestimmte Viruskonzentrationen im Gehirngewebe erreicht werden. Das Ausmaß, in dem sich das Virus im Gehirn vermehrt, wird bei Mäusen sowohl durch genetische (im Sinne der Mendelschen Gesetze) als auch durch andere Faktoren beeinflußt.

Die primären Encephalitiden sind durch Läsionen in allen Teilen des ZNS charakterisiert, die stärksten Veränderungen finden sich in den nasalen Strukturen des Gehirns und in der Großhirnrinde, im geringeren Umfang auch im Rückenmark. Stets erkennt man kleine Hämorrhagien mit perivasculären und meningealen Infiltrationen, die vorwiegend aus mononucleären Zellen bestehen. Häufig treten Nervenzelldegenerationen mit Neuronophagien auf; die Purkinje-Zellen des Kleinhirns können zerstört sein. Außerdem können encephalomalacische Herde auftreten; zellfreie Plauqes mit einer schwammartigen Struktur, in denen die markhaltigen Fasern, die Dendriten und Axonen zerstört sind, lassen sich ebenfalls feststellen. Auch beobachtet man focale Mikrogliaproliferationen. Es sind also nicht nur die Neuronen, sondern auch die Zellen des Stützgewebes des ZNS in Mitleidenschaft gezogen.
Obwohl man ausgedehnte Degenerationen der Nervenzellen bei allen Encephalitiden als Folge von Arbovirusinfektionen sieht, kann man doch gewisse Chrakteristika einzelner Virusinfektionen feststellen. So sind Läsionen als Folge einer Infektion mit EEE-Virus vor allem im Cortex zu finden, während nach Infektionen mit WEE die basalen Nuclei in erster Linie befallen sind. Die pathologisch-anatomischen Veränderungen bei SLE-Virusinfektionen treten vor allem im Hirnstamm und Mittelhirn auf. Viele Infektionen durch ZeckenencephalitisViren führen zu Veränderungen in den Vorderhornzellen des Rückenmarks, die von den bei der Poliomyelitis beobachteten nicht zu unterscheiden sind.

\section{Klinische Symptome}

Die Inkubationszeit der Encephalitiden wird auf 4-21 Tage geschätzt. Die Erkrankungen sind durch einen plötzlichen Beginn mit starken Kopfschmerzen, Schüttelfrost, Fieber, Schwindelgefühl und Erbrechen gekennzeichnet, außerdem bestehen allgemeine Schmerzen und ein deutliches Krankheitsgefühl. Innerhalb von 24-48 Std nach Beginn kann sich eine deutliche Schläfrigkeit entwickeln, die bis zur Bewußtlosigkeit fortschreiten kann. Meistens findet sich eine Nackensteife. In schweren Fällen entwickeln sich Verwirrtheitssymptome, Dysarthrie, Tremor, Krämpfe und ein Koma. Das Fieber hält etwa 4-10 Tage an. Die Sterblichkeitsrate schwankt bei den meisten Encephalitiden; sie beträgt 2-3\% bei WEE-Infektionen und $50-70 \%$ bei EEE-Infektionen. Bei der japanischen Encephalitis B hat man eine Letalität bei älteren Menschen von $80 \%$ beobachtet. Dauerschäden können auftreten, wobei Verwirrtheitssymptome, Persönlichkeitsveränderungen, Paresen, Aphasie und cerebellare Symptome beobachtet werden.

Abortive Infektionen ähneln einer abakteriellen Meningitis oder einer nicht-paralytischen Poliomyelitis. In einigen Gegenden scheinen inapparente Infektionen häufig aufzutreten. In Kalifornien, wo sowohl die westliche Pferdeencephalitis (WEE) als auch die St. Louis-Encephalitis (SLE) vorkommen, zeigt die WEE eine Prädilektion für das Kleinkindes- und Kindesalter. In dem gleichen Gebiet tritt die SLE nur selten bei Kleinkindern auf, obwohl beide Viren durch den gleichen Zwischenwirt (Culex tarsalis) übertragen werden. 


\section{Laboratoriumsdiagnose}

A. Isolierung des Virus: Das Virus tritt nur früh im Infektionsablauf und im allgemeinen vor Einsetzen der Symptome im Blut auf. Am häufigsten kann es aus dem Gehirn bei tödlich verlaufenen Erkrankungen durch intracerebrale Inoculation saugender Mäuse isoliert werden.

Konnte ein vermehrungsfähiges Agens - frei von Bakterien - erhalten werden, so muß dieses Agens durch entsprechende Neutralisation oder Komplementbindung oder Hämagglutinationshemmung mit bekannten Antiseren identifiziert werden.

B. Serologie: Innerhalb weniger Tage nach Krankheitsbeginn sind sowohl neutralisierende als hämagglutinationshemmende Antikörper nachweisbar; die komplementbindenden Antikörper bilden sich dagegen später. Die im Neutralisationstest und - wahrscheinlich auch die im Hämagglutinationshemmungstest nachweisbaren Antikörper bleiben jahrelang, wenn nicht lebenslänglich bestehen, während die in der KBR gefundenen Antikörper innerhalb von zwei bis fünf Jahren nicht mehr nachgewiesen werden können.

Der einfachste serodiagnostische Test bei derartigen Erkrankungen ist der Hämagglutinationshemmungstest, aber hierdurch wird im wesentlichen die Gruppe und weniger das einzelne ätiologisch verantwortliche Virus identifiziert. Verwendet man Erythrocyten von erwachsenen Gänsen und nicht von frisch geschlüpften Kücken, so muß das zu untersuchende Serum zuerst mit Gänseerythrocyten gemischt werden, um das in menschlichen und anderen Seren vorhandene unspezifische Hämagglutinin zu absorbieren.

In gleicher Weise wie bei anderen Infektionen ist es auch hier erforderlich, während der Infektion einen Konzentrationsanstieg der spezifischen Antikörper festzustellen, um eine Diagnose zu ermöglichen. Aus diesem Grund muß die erste Serumentnahme sobald wie möglich nach Beginn der Erkrankung und die zweite Entnahme etwa 2-3 Wochen später erfolgen. Beide Serumentnahmen müssen in dem gleichen serologischen Test untersucht werden.

Die innerhalb der Gruppen A und B vorhandenen serologischen Kreuzreaktionen müssen bei der Diagnosestellung berücksichtigt werden. So können nach einmaliger Infektion mit einem Virus dieser Gruppe auch Antikörper gegen andere Viren auftreten. Diese gruppenspezifi- schen Antikörper weisen im allgemeinen einen niedrigeren Titer als die typenspezifischen auf und sind damit meist leicht als solche zu erkennen. Die serologische Diagnose kann schwierig werden, wenn Epidemien in Endemiegebieten auftreten oder wenn eine Erkrankung bei einem Menschen auftritt, der früher durch ein nahe verwandtes Arbovirus infiziert worden war. Unter diesen Umständen kann eine endgültige ätiologische Diagnose unmöglich werden. Die Spezifität der Antikörper im Hinblick auf das ätiologisch verantwortliche Virus nimmt in der Reihenfolge neutralisierender Antikörper, komplementbindender Antikörper und hämagglutinationshemmender Antikörper ab.

\section{Immunität}

Man nimmt an, daß die Immunität nach einer einzigen Infektion dauerhaft ist. In Endemiegebieten kann man eine Immunität als Folge inapparenter Infektionen erwerben. Die Häufigkeit von Menschen mit Antikörpern gegen die lokal verbreiteten Arboviren nimmt mit zunehmendem Alter zu.

Versuche zu einer Immunisierung mit Totvaccinen haben beim Menschen noch nicht zu eindeutigen Resultaten geführt. Zum Schutz von Pferden ist eine wirksame Vaccine gegen das Virus der östlichen und westlichen Pferdeencephalitis entwickelt worden. Wirksame Impfstoffe zur Verhütung dieser Erkrankungen beim Menschen stehen gegenwärtig nicht zur Verfügung.

Gegen Infektionen mit dem Virus der Venezuela-Pferdeencephalitis (VEE) steht ein sehr guter, aus abgeschwächten Viren bestehender Impfstoff zur Verfügung, der zur Unterbrechung der Epidemien bei Pferden und auch versuchsweise beim Menschen eingesetzt werden kann.

Da verschiedene Virusarten einer Arbovirusgruppe gemeinsame Antigene besitzen, kann die Antikörperbildung nach einer Immunisierung (oder Infektion) durch ein Virus dieser Gruppe durch frühere Exposition gegenüber anderen Viren dieser Gruppe modifiziert werden. Im allgemeinen ist die homologe Reaktion stärker als die kreuzreagierenden Reaktionen. Dieser Mechanismus kann bei der Immunisierung einer Bevölkerungsgruppe gegen ein verwandtes $\mathrm{Vi}$ rus von Bedeutung sein. 


\section{Behandlung}

Es gibt keine allgemein anerkannte spezifische Behandlung. In Tierexperimenten erwies sich ein Hyperimmunserum dann als unwirksam, wenn es nach Einsetzen der Symptome verabreicht wurde. Verabreichte man es dagegen 1-2 Tage nach Eindringen des Virus, bevor sich jedoch Encephalitissymptome bemerkbar machten, so konnte der tödliche Ausgang der Infektion hierdurch verhindert werden.

\section{Epidemiologie}

Bei schwer verlaufenden, durch Encephalitisviren hervorgerufenen Epidemien kann die Erkrankungsrate etwa 1-3 pro 1000 betragen. Während der großen, 1966 in Dallas (Bevölkerung 1,0 Million) abgelaufenen Epidemie der St. Louis-Encephalitis wurden 545 Erkrankungsfälle gemeldet (darunter befanden sich 145 [27\%] durch entsprechende Laboratoriumsuntersuchungen bestätigte Erkrankungen, ferner 15 Todesfälle). Die Befallsrate der Gesamtbevölkerung betrug 15 Erkrankungen pro 100000 Einwohner, die Letalität $10 \%$. Todesfälle wurden ausschließlich bei über 45 jährigen Menschen registriert.

Die Epidemiologie der durch Arthropoden übertragenen Encephalitiden muß die Verbreitung und Erhaltung dieser Virusarten in der Natur auch in Abwesenheit des Menschen erklären. Das Virus wird von den infizierten Tieren durch den Biß eines als Vektor dienenden Arthropoden auf andere Tiere übertragen. Bei Zecken kann das Virus von der einen Generation auf die nächste transovariell weitergegeben werden, und in diesen Fällen dienen die Zecken sowohl als echtes Reservoir der Viren und auch als ihre Überträger. In den Tropen, wo die Stechmückenpopulationen während des ganzen Jahres vorhanden sind, läuft der Cyclus zwischen den als Reservoir dienenden Tieren und den Stechmücken kontinuierlich ab.

Es ist nicht bekannt, ob in Gegenden mit gemäßigtem Klima das Virus jährlich von außen (z. B. durch Zugvögel aus tropischen Gebieten) erneut eingeschleppt wird oder ob es in dem jeweiligen Gebiet irgendwie überwintert. Man könnte sich eine einfache Form der Überwinterung durch die überwinternden Mücken vorstellen, die dann die Vögel erneut infizieren würden, so daß in jedem Jahr ein einfacher VogelMücke-Vogel-Cyclus sich ausbildet. Oder aber das Virus bleibt während dieser Zeit in Vögeln,
Säugern oder Arthropoden latent. Die Bedeutung von Kaltblütern (Schlangen, Schildkröten, Eidechsen, Alligatoren, Fröschen) für die Ökologie einzelner Arboviren konnte bisher nicht eindeutig geklärt werden. Bestimmte Schlangenarten, die experimentell mit WEE-Virus infiziert worden waren, können überwintern, und bei ihnen konnte im folgenden Frühjahr über einen langen Zeitraum Virus in hoher Konzentration nachgewiesen werden. Normale Mücken konnten durch Füttern an diesen Schlangen infiziert werden und das Virus weiter verbreiten. Diese Experimente zeigen einen möglichen Weg der Überwinterung der Arboviren auf, zumal das Virus auch im Blut wildlebender Schlangen nachgewiesen werden konnte. Das Reservoir von VEE sind wahrscheinlich wildlebende Nagetiere; wenn das Virus einmal in einem Gebiet auftritt, ist es deshalb nur schwer wieder auszurotten (siehe unten).

A. Serologische Epidemiologie: Untersuchungen über die Verbreitung von Antikörpern in der normalen Bevölkerung haben gezeigt, daß in Endemiegebieten fast die gesamte Bevölkerung infiziert worden war und daß der größte Teil dieser Infektionen asymptomatisch verlief.

Bei der 1964 in Houston abgelaufenen Epidemie von St. Louis-Encephalitis ( 712 Erkrankungen wurden gemeldet) beobachtete man bei entsprechenden Untersuchungen willkürlich ausgewählter Bewohner der Stadt eine Rate inapparenter Infektionen von $8 \%$. Untersuchte man dagegen Bewohner jener Stadtviertel, wo die meisten Erkrankungsfälle auftraten, so betrug dieser Anteil 34\%. Die relative Anzahl Erkrankter, gemessen an der Gesamtzahl Infizierter, war jedoch in beiden Fällen gleich. Natürlich müssen infizierte Stechmücken vorhanden sein, bevor Infektionen bei Menschen auftreten können, wobei allerdings sozio-ökonomische Faktoren (Aufenthalt außerhalb des Hauses, Fliegengitter, Belüftungsanlagen) das Ausmaß der Exposition einzelner Bevölkerungsgruppen gegenüber diesen Virusträgern bestimmen.

In Endemiegebieten, wie z.B. Kalifornien, werden $11 \%$ der Kinder mit diaplacentar übertragenen Antikörpern gegen WEE geboren, und $27 \%$ besitzen Antikörper gegen SLE. Zwischen der Länge des Aufenthaltes der Mutter in diesem Endemiegebiet und dem Erwerb von Antikörpern gegen die Erreger besteht eine direkte Beziehung. 
B. Durch Mücken übertragene Encephalitiden: Es kommt zu einer Infektion des Menschen, wenn Mücken wie Culex tarsalis, Culex quinquefasciatus, Culex pipiens oder Culex tritaeniorhynchus (Japan) oder auch andere Arthropoden zuerst ein infiziertes Tier und danach einen Menschen stechen.

Die Erreger der Pferdeencephalitiden, WEE, VEE und EEE, werden durch Stechmücken der Gattung Culex auf Pferde oder Menschen übertragen; Ausgang ist ein Stechmücke-WildvogelStechmücke-Cyclus. Pferde - und auch der Mensch - werden hierbei nur am Rande berührt und sind für die Aufrechterhaltung des Virus in der Natur ohne Bedeutung. Wenn Encephalitiden bei Menschen in Zusammenhang mit einer Krankheitshäufung bei Pferden auftreten, so sollten Ärzte und der öffentliche Gesundheitsdienst stets an eine beginnende Arbovirus-Epidemie denken. VEE und EEE verlaufen bei Pferden im allgemeinen schwer, bis zu $90 \%$ der Tiere sterben innerhalb der ersten zwei Tage. WEE ist im Gegensatz hierzu meist nicht mit einer so hohen Todesrate begleitet. Außer bei Pferden kann EEE auch bei Ziervögeln, wie z.B. Fasanen, Pekingenten, Rebhühnern, epidemische Krankheitshäufungen verursachen. Auch bei Infektionen mit SLE und JBE-Viren beobachtet man den Stechmücke-Wildvogel-Stechmücke-Cyclus, obwohl - vor allem bei dem letzteren Virus - auch Schweine als Viruswirt in Betracht kommen. Die Stechmücken bleiben lebenslänglich (mehrere Wochen bis Monate) infektiös. Lediglich das Weibchen saugt Blut, nimmt dabei das Virus auf und überträgt es auf andere Wirte. Die Zellen des mittleren Darmabschnittes der Mükken sind als Stelle der primären Virusvermehrung anzusehen. Hiernach kommt es zu einer Virämie und schließlich zum Eindringen des Virus in verschiedene Organe, vor allem die Speicheldrüsen und das Nervensystem, wo eine sekundäre Virusvermehrung auftritt. Der Arthropode zeigt während der ganzen Virusvermehrung keine Krankheitssymptome.

Eine Arbovirusinfektion bei insektenfressenden Fledermäusen verursacht eine Virämie, die etwa 6-12 Tage dauert, ohne daß die Tiere irgendwelche Krankheitssymptome oder pathologische Veränderungen zeigen. Bei diesen Fledermäusen entwickelt sich dann eine Virämie, und sobald die Viruskonzentration hoch genug ist, kann die infizierte Fledermaus wiederum als Infektionsquelle für andere Mücken dienen, die die Infektion auf Hühner sowie auf weitere Fledermäuse übertragen können.

In der Natur leben die Mücken mit den Fledermäusen in einer engen Gemeinschaft, nicht nur im Sommer tagsüber auf den Rastplätzen, sondern auch bei der Überwinterung. In Experimenten waren die Mücken unter bestimmten Voraussetzungen in der Lage, das Virus auf die Fledermäuse zu übertragen. Die hierbei infizierten Fledermäuse zeigten ohne Auftreten einer Virämie eine latente Infektion, die drei Monate lang bei $10^{\circ} \mathrm{C}$ unter diesen imitierten Überwinterungsbedingungen nachweisbar war. Wurden die Fledermäuse in eine normale Raumtemperatur zurückgebracht, so fand sich drei Tage später bei diesen Tieren eine Virämie. Die nach der Hibernation bei den Tieren festgestellten Virustiter lagen über dem zur Infektion von Mücken erforderlichen Minimalwert. Dieser Mücke-Fledermaus-MückeCyclus kann somit vielleicht auch als ein Mechanismus für die Überwinterung einiger Arboviren angesehen werden.

\section{Durch Zecken übertragene Encephalitiden:}

1. Russische Frühjahrs-Sommer-Encephalitis: Diese Erkrankung tritt hauptsächlich im Frühsommer, vor allem bei erwachsenen Männern auf, die mit den Zecken Ixodes persulcatus oder Ixodus ricinus in verwilderten Wäldern in Berührung gekommen sind. Zecken können in jedem Stadium ihrer Metamorphose infiziert werden und das Virus anschließend transovariell übertragen. Man nimmt an, daß das Virus in der Zecke oder in Wirbeltieren (Igel, Haselmäuse, Fledermäuse) überwintert. Der Virus wird mit der Milch infizierter Ziegen über einen langen Zeitraum ausgeschieden und die Infektion kann durch den Genuß unpasteurisierter Ziegenmilch auf den Menschen übertragen werden. Charakteristisch für diese Erkrankung ist eine Beteiligung der bulbären oder cervicalen Abschnitte des Rückenmarks und die Ausbildung von ascendierenden Lähmungen oder Hemiparesen.

2. Louping ill: Diese Erkrankung der Schafe in Schottland und im nördlichen England wird durch die Zecke Ixodes ricinus übertragen. Gelegentlich kann auch der Mensch infiziert werden.

3. Zeckenencephalitis (zentraleuropäische oder biphasische Meningoencephalitis, FrühsommerMeningoencephalitis): Dieses Virus ist mit dem RSSE- und dem ,louping ill“-Virus verwandt. 
Typische Erkrankungsfälle zeigen einen biphasischen Verlauf, wobei die erste Phase einem uncharakteristischen fieberhaften Infekt und die zweite Phase einer Meningoencephalitis mit oder ohne Paresen gleicht.

4. Kyasanur-Waldkrankheit: Diese in Indien auftretende hämorrhagische Erkrankung wird durch ein Virus der Gruppe der russischen Frühjahrs-Sommer-Encephalitis verursacht. In den südlichen Teilen Indiens können außer dem Menschen gelegentlich verschiedene Affenarten (Presbytis entellus, Macaca radiata) durch diese Erreger infiziert werden.

5. Powassan-Encephalitis: Dieses durch Zekken übertragene Virus gehört ebenfalls zur Gruppe der russischen Frühjahrs-Sommer-Encephalitis. Infektionen des Menschen treten nur selten auf. Nachdem 1959 über den ersten Erkrankungsfall in Kanada berichtet wurde, sind 6 weitere Fälle beobachtet worden, die alle in den nordöstlichen Gebieten der USA auftraten.

Jedes Virus ist auf ein bestimmtes Gebiet begrenzt. Man hat angenommen, daß diese Viren auf eine gemeinsame Vorstufe zurückgehen und dann an verschiedene Gegenden der Welt adaptiert wurden, wobei jedes Virus seinen speziellen Arthropoden als Überträger und sein eigenes tierisches Reservoir besitzt. Auf der anderen Seite ist es möglich, ein Virus aus einem bestimmten Gebiet herauszuhalten, da das hier verbreitete lokale Virus eine Immunität in der Bevölkerung aufgebaut hat, die wegen der überlappenden serologischen Reaktionen auch gegen andere Viren schützt. Hierdurch wird vielleicht der Mittlere Osten, wo West Nile-Fieber vorherrscht, aus dem Verbreitungsgebiet der japanischen B-Encephalitis ausgespart.

Ähnliche Verhältnisse kann man auch im Gebiet der Karibischen See antreffen, wo die Dengue eine allgemein verbreitete Infektion ist und wo die Antikörper gegen die Dengueviren einen Schutz gegen das Gelbfieber- oder SLEVirus bieten. Da bei der Übertragung dieser Erkrankungen häufig die gleichen Stechmückenarten beteiligt sind, kann vielleicht auch eine Interferenz die Insekten an der gleichzeitigen Übertragung beider Erkrankungen hindern.

\section{Kontrolle}

Eine biologische Kontrolle der als natürliche Wirte dieser Viren dienenden Wirbeltiere .-.. vor allem Vögel — ist praktisch unmöglich. Die wirksamste Kontrolle besteht deshalb in einer Bekämpfung der als Überträger dienenden Insekten. Da die Virämie in dem Wirbeltier meist nur recht kurzdauernd ist (3-6 Tage bei SLE-Infektionen der Vögel), kann jede Bekämpfung der Vektoren zu dieser Zeit zu einer Unterbrechung des Infektionscyclus führen. Während der 1966 in Dallas ablaufenden SLEEpidemie wurden kleine Mengen hochkonzentrierter Insecticide vom Flugzeug aus in der gesamten Umgebung abgeregnet. Hierdurch wurde eine deutliche Senkung der Anzahl infizierter Insekten erzielt.

Die Anwendung von Impfstoffen aus inaktivierten Viren brachte bisher keinen deutlichen Erfolg. Zur Zeit werden mehrere, aus vermehrungsfähigen abgeschwächten (attenuierten) Viren bestehende Impfstoffe erprobt. Eine derartige Lebendvaccine wurde 1971 erfolgreich bei einer schweren VEE-Epidemie bei Pferden in Texas eingesetzt.

\section{Venezuela-Pferdeencephalitis}

Die Venezuela-Pferdeencephalitis (VEE) ist eine durch Stechmücken übertragene Viruserkrankung, die sich beim Menschen als uncharakteristische fieberhafte Erkrankung und bei Pferden als Encephalitis äußert.

\section{Eigenschaften des Virus}

VEE, ein RNS-haltiges Virus, gehört zur Gruppe der Arboviren und wird durch Äther und durch Desoxycholat rasch inaktiviert. Die Virionen haben einen Durchmesser von 60 bis $75 \mathrm{~nm}$ und sind aus einer Lipoproteid-haltigen Hüllmembran und einem sphärischen Innenkörper (Nucleoid) mit einem Durchmesser von 30-40 nm zusammengesetzt. Das Virus ist relativ Hitze-labil. Die gegen VEE immunen Tiere besitzen eine erhöhte Resistenz gegen EEE-Infektion, umgekehrt trifft das dagegen nicht im gleichen Umfang zu. Nach experimenteller Infektion tötet VEE Mäuse, Meerschweinchen, Hamster und Eintagskücken; das Virus wird in den Faeces, Urin und in den Nasensekreten dieser Tiere ausgeschieden. VEE-Virus ist cytopathogen für Babyhamster-Nierenzellen (BHKZellen), HeLa-, Entenembryo-, Vero(Affennieren-Zellstamm)- und Hühnerembryonalzellkulturen. 


\section{Klinische Befunde}

Nach einer Inkubationszeit von 24-72 Std zeigen mehr als die Hälfte der infizierten Pferde Symptome von seiten des Zentralnervensystems, während bei den restlichen Tieren nur ein uncharakteristisches Fieber besteht. $\mathrm{Zu}$ den Symptomen gehören hohes Fieber, Abgeschlagenheit, Diarrhoe, Appetitlosigkeit und Gewichtsverlust. In den nicht tödlich endenden Fällen geht das Fieber zurück und die Erholung setzt verzögert ein. In den tödlich endenden Erkrankungsfällen bleibt das Fieber dagegen bestehen, eine allgemeine Müdigkeit setzt ein, das Pferd zeigt Gleichgewichtsstörungen; der Tod tritt in 2-4 Tagen ein.

Die Erkrankung des Menschen ist dagegen bei etwa $97 \%$ der Patienten Influenza-ähnlich; man beobachtet hohes Fieber, Kopfschmerzen und schwere Myalgien, die Erholung ist häufig verzögert. Bei etwa 3\% der Infizierten besteht ein encephalitisches Bild. Die Letalität wird mit etwa $0,5 \%$ angegeben, die vor allem junge Menschen mit neurologischen Symptomen betrifft. Sowohl beim Mensch als auch beim Pferd beobachtet man im übrigen eine Leukopenie.

\section{Laboratoriumsdiagnose}

Das Virus kann aus Blut, Serum, Nasopharyngealflüssigkeit, vielen Organen und gelegentlich aus dem in der akuten Krankheitsphase entnommenen Liquor isoliert werden. Die Isolierung erfolgt im allgemeinen durch intracerebrale Inoculation saugender Mäuse oder durch Verimpfung des Untersuchungsmaterials in Zellkulturen. Die Antikörperbildung gleicht den Beobachtungen bei anderen Arbovirus-Infektionen. Frühzeitig treten neutralisierende und hämagglutinationshemmende Antikörper auf, die auch persistieren, während die in der KBR nachweisbaren Antikörper erst 2-3 Wochen nach Beginn der Erkrankung auftreten und in den folgenden 2-5 Jahren wieder verschwinden. Die Spezifität der serologischen Tests nimmt in der Reihenfolge Neutralisationstest, Komplementbindungsreaktion, Hämagglutinationshemmungstest ab. Bei der zuletzt genannten Reaktion finden sich deutlich Kreuzreaktionen mit anderen Viren der Gruppe A; die homologen Antikörpertiter sind jedoch höher als die heterologen.

\section{Epidemiologie}

Am natürlichen Cyclus von VEE sind wahrscheinlich Säuger und Stechmücken beteiligt; Vögel und Fledermäuse sind für dieses Virus auch empfänglich. Der Mensch wird nur gelegentlich in diesen Cyclus einbezogen.

Nach den ersten Berichten über VEE aus Venezuela im Jahr 1936 trat die Erkrankung anschließend auch in Panama und Mexiko auf. 1971 trat eine schwere Epidemie entlang der Grenze zwischen Texas und Mexiko auf, bei der mehrere Tausend Todesfälle bei Pferden und mehrere Hundert menschliche Erkrankungen auftraten.

In Florida ist VEE bei Nagetieren endemisch verbreitet. Nach serologischen Untersuchungsbefunden muß man annehmen, daß hier auch zahlreiche subklinische Infektionen bei Menschen auftreten; klinische Erkrankungen mit ZNS-Symptomen sind jedoch selten.

Es sind mehrere Subtypen des VEE-Virus bekannt, die sich in ihrer krankheitsauslösenden Fähigkeit bei Mensch und Tier unterscheiden. Die Seltenheit klinischer Erkrankungen in Florida beruht vielleicht auf der endemischen Verbreitung eines weniger virulenten Subtyps in Florida als in den übrigen Gebieten im Südwesten der USA.

\section{Kontrolle}

Da im mexikanischen Grenzbereich virulentes VEE-Virus weit verbreitet ist, wurde die Schutzimpfung aller Pferde (einschließlich einer Wiederimpfung früher bereits geimpfter Tiere) mit einem Lebendimpfstoff durchgeführt; auBerdem wurde seit 1972 mit einer lokalen und auch einer von Flugzeugen aus vorgenommenen Mückenbekämpfung begonnen. Diese Maßnahmen haben bisher zu einer Begrenzung der Krankheitsausbreitung geführt. Außerdem sind strenge Quarantänemaßnahmen erforderlich, um eine Verschleppung der Krankheit in infektionsfreie Gebiete zu verhindern. Der Lebendimpfstoff wurde auch versuchsweise beim Menschen angewendet, steht jedoch nicht zur allgemeinen Anwendung zur Verfügung.

\section{Bunyavirus-Encephalitis (California-Encephalitis)}

In der California-Gruppe faßt man 11 eng miteinander verwandte, in ihrer Antigenität 
jedoch verschiedene Virusarten zusammen. Diese Gruppe ist Teil eines größeren Komplexes von Viren, der Bunyamwera-Gruppe; die Verwandtschaft wurde durch Kreuzreaktionen bei Neutralisations- und Hämagglutinationstest sowie bei Komplementbindungsreaktionen festgestellt.

\section{Eigenschaften der California-Gruppe}

Die Virionen sind sphärisch und besitzen einen Durchmesser von 80-100 $\mathrm{nm}$, sie werden durch Natriumdesoxycholat und Äther inaktiviert. Hämagglutine sind bei diesen Viren nachweisbar. Alle Viren der California-Gruppe sind pathogen für saugende Mäuse und Hamster sowie für eine Vielzahl von Zellkulturen.

\section{Klinische Befunde und Diagnose}

Der Beginn einer Encephalitis nach Infektion mit dem California-Encephalitis-Virus ist meist abrupt; im typischen Fall bestehen starke Stirnkopfschmerzen, denen ein Fieberanstieg auf $38,3^{\circ} \mathrm{C}$ bis $40,4^{\circ} \mathrm{C}$ vorangeht. Außerdem können Erbrechen, Lethargie und focale oder generalisierte hirnorganische Anfälle auftreten. Weniger häufig findet man ausschließlich eine abakterielle Meningitis mit Nackensteife.

Häufig läßt sich eine Leukocytose aus polymorphkernigen Leukocyten nachweisen, wobei im peripheren Blutbild Leukocytenzahlen bis $29000 / \mathrm{mm}^{3}$ gefunden werden können. Im Liquor besteht eine Pleocytose, die vorwiegend lymphocytär ist $\left(30-1000\right.$ Zellen $\left./ \mathrm{mm}^{3}\right)$. Im EEG findet man das Bild einer allgemeinen Dysfunktion mit langsamen Wellen hoher Amplitude.

Bei histopathologischer Untersuchung lassen sich Nervenzelldegenerationen und herdförmige Entzündungsherde mit einigen perivasculären Infiltraten und Ödemen im cerebralen Cortex und in den Meningen nachweisen. Deutliche neurologische Dauerschäden sind selten; doch bleiben EEG-Veränderungen bei schweren Krankheitsfällen mindestens 1-2 Jahre bestehen.

Eine serologische Bestätigung der Diagnose durch HHT, NT oder KBR ist bei allen Verdachtsfällen erforderlich.

\section{Epidemiologie}

Das erste Virus dieser Gruppe, das CaliforniaEncephalitis-Virus, wurde 1943 aus Stechmük- ken in Kalifornien isoliert. Größere Ausbrüche wurden jedoch erstmals 1964 beobachtet und näher untersucht.

Erkrankungen treten vor allem von Ende Juli bis Anfang September in ländlichen Gegenden vor allem am oberen Mississippi und Ohio (Indiana, Wisconsin, Ohio) auf; vereinzelte Fälle wurden auch aus North Carolina. Minnesota, Iowa, New York, Florida, Kalifornien und aus Louisiana berichtet. Klinisch manifeste Erkrankungen traten ausschließlich bei Personen unter 21 Jahren auf, die Mehrzahl der Fälle war zwischen 4 und 14 Jahre alt.

Nach den zur Verfügung stehenden ökologischen Befunden scheint die Infektion zwischen verschiedenen, vorwiegend in Wäldern vorkommenden Stechmücken und kleinen Säugern (Eichhörnchen, Kaninchen) übertragen zu werden. Die Infektion des Menschen ist nur ein Nebenweg. Der Überwinterungsmechanismus des Virus ist unbekannt. Bei dem Lacrosse-Virus, einem weiteren Mitglied der CaliforniaGruppe, fand man jedoch ein Überwintern des Virus in den Eiern der als Überträger dienenden Steckmücke. Das Virus wird transovariell übertragen; die aus den infizierten Eiern hervorgehenden Imagines können das Virus übertragen.

\section{West Nile-Fieber}

West Nile-Fieber ist eine akute, milde, fieberhafte Erkrankung, die mit einer Lymphadenophatie und einem Exanthem einhergeht und die im Vorderen Orient, in tropischen und subtropischen Gebieten Afrikas und im südwestlichen Asien auftritt.

\section{Eigenschaften des Virus}

Das Virus besitzt die Eigenschaften der übrigen Arboviren der Gruppe B. Es vermehrt sich im Hühnerembryo und in Gewebekulturen, wobei es Plaques auf einschichtigen Zellkulturen unter Agar bildet.

\section{Klinische Befunde}

Das Virus wird durch den Stich einer Mücke der Gattung Culex übertragen. Der Erreger führt zu einer Virämie und einer generalisierten Infektion, die durch eine Lymphadenopathie gekennzeichnet ist und gelegentlich von einem maculopapulösen Exanthem begleitet wird. Selten kann es auch einmal zu einer vorübergehenden me- 
ningealen Reizung während des akuten Krankheitsstadiums kommen. Bei alten Menschen, die eine verlangsamte und erniedrigte Antikörperbildung zeigen, kann dieser Erreger auch einmal zu einer tödlich endenden Encephalitis führen.

\section{Laboratoriumsdiagnose}

Das Virus kann aus Blut im akuten Stadium der Infektion isoliert werden. Zur Durchführung serologischer Tests muß die erste Blutprobe so früh wie möglich im Krankheitsablauf entnommen werden, während die zweite etwa 2-3 Wochen später gesammelt wird. Sowohl der Neutralisationstest, der Hämagglutinationshemmungstest als auch die Komplementbindungsreaktion können zum Nachweis der Antikörper verwendet werden. In den während der Rekonvaleszenz entnommenen Blutproben findet man in der Komplementbindungsreaktion im allgemeinen Titer von $1: 32$ bis $1: 128$; die Antikörper bleiben in dieser Titerhöhe etwa drei Monate lang nachweisbar und fallen dann langsam in den nächsten zwei Jahren auf niedrigere Titerwerte ab. Die homologen neutralisierenden Antikörper steigen etwas langsamer an, erreichen ihre höchste Titerhöhe nach etwa vier Monaten und bleiben etwa zwei Jahre lang in dieser Titerhöhe bestehen. Während der Rekonvaleszenz entwickeln sich heterologe komplementbindende und neutralisierende Antikörper gegen die Viren der japanischen B-Encephalitis und der St. Louis-Encephalitis, die Mitglieder der gleichen Virusgruppe sind.

\section{Immunität}

Es kommt offenbar nur ein Antigentyp des West Nile-Virus vor; die Immunität gegen dieses Virus hält lebenslänglich an. Mütterliche Antikörper werden diaplacentar auf die Neugeborenen übertragen und innerhalb der ersten 6 Lebensmonate abgebaut.

\section{Epidemiologie}

West Nile-Fieber scheint auf den Mittleren Osten beschränkt zu sein. Antikörper gegen den Erreger konnte man jedoch bei Erwachsenen in Afrika, Indien und in Korea nachweisen. Die Befallsrate ist in einer nicht-immunen Bevölkerung sehr hoch, auch abortive und inapparente Infektionen treten auf. In einigen Gebieten, wie z. B. in Kairo, herrschen die inapparenten Infektionen vor, wobei über $70 \%$ der Einwohner im
Alter von vier Jahren und älter neutralisierende und komplementbindende Antikörper gegen dieses Virus besitzen.

Diese Sommerkrankheit tritt in ländlichen Gebieten häufiger als in Städten auf. Aus Culex konnte bei verschiedenen Gelegenheiten während epidemischer Häufungen von Erkrankungen dieses Virus isoliert werden. Die Mücken sind auch im Laboratorium infizierbar; nach einer externen Inkubationszeit von 1-3 Wochen können sie die Erkrankung übertragen.

Auch Zecken können als Reservoir und als Überträger des West Nile-Fiebers von Bedeutung sein. Nymphen der Zecke Ornithodorus moubata können durch Saugen an Mäusen während der virämischen Phase infiziert werden. Das Virus vermehrt sich in der Nymphe und bleibt in der reifen Imago mindestens 224 Tage lang nachweisbar. Die Zecken können wiederum das Virus auf Hühner und Mäuse durch den Saugakt übertragen.

\section{Kontrolle}

Eine Mückenbekämpfung ist die logische Kontrollmaßnahme, die sich bis jetzt allerdings noch nicht als wirksam erwiesen hat.

\section{Gelbfieber}

Gelbfieber ist eine akute, fieberhafte, durch Mücken übertragene Erkrankung. Schwere Krankheitsfälle sind durch Gelbsucht, Proteinurie und Hämorrhagien charakterisiert.

Gelbfieber-Virus ist die Prototyp-Species des Genus Flavivirus in der Familie Togaviridae.

\section{Eigenschaften des Virus}

A. Größe: Das Gelbfieber-Virus besitzt einen Durchmesser von etwa $22-38 \mathrm{~nm}$.

B. Verhalten gegeniiber chemischen und physikalischen Einfliissen: Das Virus kann etwa einen Monat lang bei $4^{\circ} \mathrm{C}$ aufbewahrt werden, 3 Monate lang in $50 \%$ Glycerin bei $0^{\circ} \mathrm{C}$ und jahrelang bei $-70^{\circ} \mathrm{C}$. Nach Lyophilisieren bleibt es bei $0^{\circ} \mathrm{C}$ jahrelang infektiös. Das Virus wird durch $10 \mathrm{~min}$ langes Erhitzen auf $60^{\circ} \mathrm{C}$ abgetötet und ebenfalls durch eine $48 \mathrm{Std}$ lange Einwirkung von $0,1 \%$ Formalin bei $0^{\circ} \mathrm{C}$ inaktiviert.

C. Empfänglichkeit von Tieren und Vermehrung des Virus: Das Gelbfiebervirus vermehrt sich in einer Vielzahl verschiedener Tiere (Af- 
fen, Mäuse, Meerschweinchen), ferner kann es sich auch in Mücken vermehren. Der Erreger ist ohne Schwierigkeiten in embryonierten Hühnereiern und in Gewebekulturen aus embryonalen Hühner- und Mäusezellen zu vermehren. Alle Stämme führen nach intracerebraler Inoculation von Mäusen zu einer Encephalitis. Diese Encephalitis tritt bei jugendlichen Mäusen auch nach subcutaner und intraperitonealer Verabreichung auf.

Frisch isolierte Virusstämme (von Menschen, Affen oder Mücken) verhalten sich pantrop, d.h. sie befallen Zellen aller drei embryonalen Zellagen. Diese Stämme führen nach subcutaner und intraperitonealer Inoculation von Affen zu einer schweren (im allgemeinen tödlich verlaufenden) Infektion mit einem deutlichen Leberschaden. Nach fortlaufender Hirn-zu-HirnPassage bei Affen und Mäusen verlieren solche Stämme viel von ihrem Viscerotropismus. Sie führen nach intracerebraler Inoculation dann zu einer Encephalitis, nach subcutaner Infektion jedoch lediglich $\mathrm{zu}$ einer asymptomatischen Infektion. Zwischen den pantropen und den neurotropen Stämmen besteht eine Kreuzimmunität.

Durch fortlaufende Passagen eines pantropen Stammes des Gelbfiebervirus in Gewebekulturen wurde der relativ avirulente $17 \mathrm{D}$-Stamm erhalten. Dieser Stamm hat seine Fähigkeit, bei Affen und Menschen eine viscerotrope oder neurotrope Erkrankung zu induzieren, verloren und wird jetzt als Vaccine verwendet. Das in der Vaccine enthaltene Virus kann 10000 fach verdünnt werden und ruft bei den intracerebral hiermit inoculierten Mäusen immer noch eine tödlich endende Encephalitis hervor.

D. Antigenität: Aus infizierten Organen können ein komplementbindendes Antigen und ein Hämagglutinin hergestellt werden. Jedes Antigen besteht aus zwei voneinander abtrennbaren Komponenten, von denen eine mit dem infektiösen Virus verknüpft ist. Die andere Komponente ist wahrscheinlich nicht das Virus, sondern ein Produkt der Zelle nach ihrer Infektion mit Gelbfiebervirus. Aufgrund serologischer Tests läßt sich das Gelbfiebervirus als ein Mitglied der Gruppe B der durch Arthropoden übertragenen Viren einstufen.

\section{Pathogenese und Pathologie}

Unsere Kenntnisse über die Pathogenese des Gelbfiebers beruhen auf Untersuchungen über die experimentelle Infektion des Affen. Das Virus dringt durch die Haut ein und breitet sich dann bis zu den lokalen Lymphknoten aus, in denen es sich vermehrt. Von den Lymphknoten dringt es in die Blutbahn ein und setzt sich in Leber, Milz, Niere, Knochenmark und im lymphatischen Gewebe fest, wo es mehrere Tage persistieren kann.

Die beim Gelbfieber gefundenen pathologisch-anatomischen Läsionen sind die Folge der Haftung und Vermehrung des Virus in einem bestimmten Organ. Der Tod ist wahrscheinlich die Folge der schweren Nekrosen in der Leber und in den Nieren, die die deutlichsten Veränderungen zeigen. Bei schweren Erkrankungsfällen kann es zu einer fast vollständigen Zerstörung des Leberparenchyms kommen. Bei tödlich endenden Gelbfiebererkrankungen finden sich häufig Hämorrhagien in der Mucosa am Pylorus-nahen Teil des Magens.

Die nekrotischen Zellen sind in der Leber fleckförmig verteilt, treten jedoch vorwiegend in den mittleren Abschnitten der Leberläppchen auf; die Nekrose ist hyalin und kann auf das Cytoplasma der Zellen beschränkt sein. Die irregulär geformten hyalinen Massen sind eosinophil und werden als Councilman-Körperchen bezeichnet. Außerdem kann man intranucleäre Einschlußkörperchen finden, die auch einigen diagnostischen Wert besitzen. Hämorrhagien in der Leber sind selten. In der Rekonvaleszenz werden die parenchymatösen Zellen erneuert und die Leberfunktion wird vollständig ohne irgendwelche Zeichen einer Beeinträchtigung wieder hergestellt.

Die Läsionen in den Nieren bei einer Infektion durch Gelbfiebervirus sind durch eine fettige Degeneration des Tubulusepithels charakterisiert. Ferner beobachtet man degenerative Veränderungen in der Milz, in den Lymphknoten und im Herzen. Intranucleäre acidophile Einschlußkörper können auch in den Nerven- und Gliazellen des Gehirns vorhanden sein. Hier im Gehirn treten außerdem perivasculäre Infiltrate mit mononucleären Zellen auf.

\section{Klinische Befunde}

Die Inkubationszeit beträgt 3-6 Tage. Die Erkrankung beginnt mit Fieber, Schüttelfrost, Kopfschmerzen und Rückenschmerzen; darauf folgt rasch Schwindelgefühl und Erbrechen. Nach diesen Prodromalsymptomen kommt es 
häufig zu einer kurzdauernden Remission. Etwa am 4. Tag beginnt die Intoxikationsperiode mit einer relativen Bradykardie (90-100) bei hohem Fieber; außerdem tritt ein mäßiger Ikterus auf. In schweren Fällen beobachtet man eine deutliche Proteinurie und Zeichen der Hämorrhagie, wobei wegen dieser Blutungsneigung das Erbrochene schwarz aussehen kann. Im Blutbild läßt sich eine Lymphopenie feststellen. Bei jenen Patienten, bei denen die Erkrankung bis zu einem schweren Stadium fortgeschritten ist (Erbrechen schwarzer Massen und Gelbsucht), ist die Letalität hoch. Auf der anderen Seite kann die Infektion aber auch so milde verlaufen, daß sie unbemerkt vorübergeht. Gleichgültig wie schwer das Krankheitsbild ablief, es entstehen keine Dauerschäden, die Patienten erliegen entweder der Erkrankung oder erholen sich vollständig.

\section{Laboratoriumsdiagnose}

A. Virusisolierung: Bis zum 5. Tag der Erkrankung kann das Virus aus dem Blut isoliert werden. Intracerebral mit dem Serum eines Verdachtsfalles inoculierte Mäuse sterben an einer Encephalitis, falls in dem Untersuchungsmaterial Virus vorhanden war. Nachdem das Virus isoliert wurde, muß es durch einen Neutralisationstest mit spezifischen Antiseren identifiziert werden.

Bei der Erstisolierung von Menschen verhalten sich einige Virusstämme ,,paradox“. Hierbei treten nach Verimpfung des unverdünnten Serums keine Krankheitssymptome bei den Mäusen auf, während das gleiche Serum in den Verdünnungen 1:10 oder 1:100 eine Encephalitis bei den inoculierten Mäusen hervorrufen kann. Dieses ,,paradoxe“ Verhalten kann folgende Ursachen haben: 1. Im Serum sind Antikörper in geringer Konzentration vorhanden und das Virus liegt in einem neutralen Virus-Antikörper-Gemisch vor. Durch einfache Verdünnung kann dieser Virus-AntikörperKomplex teilweise gespalten werden und damit wird das Virus reaktiviert. 2. Außer dem infektiösen Virus ist ein verhältnismäßig großer Anteil von inaktivem Virus in der Serumprobe vorhanden, das mit der Vermehrung des aktiven Virus interferiert, wenn diese Serumprobe nicht verdünnt wird. Aus diesen Gründen muß das Serum unverdünnt in eine Gruppe und in verschiedenen Verdünnungen in weitere Gruppen von Mäusen inoculiert werden.
B. Serologie: Auch bei schweren und tödlich verlaufenden Fällen entstehen bereits frühzeitig neutralisierende Antikörper (um den 5. Tag). Bei den Patienten, die die Infektion überleben, bleiben die Antikörper im Serum lebenslänglich nachweisbar.

Komplementbindende Antikörper findet man nach milde verlaufenden Infektionen oder nach Impfungen mit dem abgeschwächten vermehrungsfähigen $17 \mathrm{D}$-Stamm im allgemeinen nicht. Bei schwer verlaufenen Infektionen kann man sie nach dem Auftreten der neutralisierenden Antikörper feststellen, ihre Titerhöhe fällt jedoch rascher ab als diese.

Die serologische Reaktion auf eine Gelbfieberinfektion kann zwei verschiedene Formen zeigen. Bei einer Primärinfektion mit dem Gelbfiebervirus entstehen zuerst spezifische hämagglutinationshemmende Antikörper, denen Antikörper gegen die anderen Viren der B-Gruppe rasch folgen. Die homologen hämagglutinationshemmenden Antikörpertiter sind jedoch stets höher als die heterologen. Die mit der Komplementbindungsreaktion nachweisbaren Antikörper steigen dagegen in ihrer Titerhöhe langsamer an; sie sind im allgemeinen von gleicher Spezifität wie die neutralisierenden Antikörper bei einer Primärinfektion.

Nach einer Zweitinfektion, d.h. einer Gelbfieberinfektion bei Patienten, die früher eine Infektion mit einem anderen Virus der BGruppe durchgemacht hatten, kommt es dagegen zu einer sehr raschen und deutlichen Bildung hämagglutinationshemmender und komplementbindender Antikörper. Eine Spezifität dieser Antikörper ist nicht einmal andeutungsweise vorhanden. Tatsächlich werden die höchsten Titer hämagglutinationshemmender und komplementbindender Antikörper gegen heterologe Viren erreicht. Die heterologe Reaktion der neutralisierenden Antikörper kann so ausgeprägt sein, daß es unmöglich wird, eine spezifische Diagnose durch den Neutralisationstest zu stellen.

Die histologische Untersuchung der Leber ist bei tödlich verlaufenden Fällen in Endemiegebieten eine wertvolle diagnostische Hilfe.

\section{Immunität}

Zwischen den in Afrika und Südamerika isolierten Gelbfiebervirusstämmen bestehen geringe Unterschiede in ihrer Antigenität. Der Prototypstamm pantroper Gelbfieberviren, der Asibi- 
Stamm, unterscheidet sich etwas von dem zur Impfung verwendeten $17 \mathrm{D}$-Stamm.

Ein von einer immunen Mutter geborenes Kind besitzt bei der Geburt Antikörper, die während der ersten sechs Lebensmonate langsam verlorengehen. Der erneute Erwerb ähnlicher Antikörper hängt von der individuellen Exposition gegenüber dem Virus unter den natürlichen Bedingungen oder von einer Impfung $a b$.

\section{Epidemiologie}

Man kennt zwei unterschiedliche epidemiologische Verhaltensweisen des Gelbfiebers: 1. Klassisches (oder Städte-)Gelbfieber; 2. Wald(oder Dschungel-)Gelbfieber. Bei dem Städtegelbfieber erfolgt die Übertragung des Virus von Mensch zu Mensch durch Stechmücken der Gattung Aedes, die in oder in der Nähe menschlicher Wohnungen leben. In der westlichen Hemisphäre und in Westafrika erfolgt die Übertragung vor allem durch $\mathrm{A}$. aegypti, die in Wasseransammlungen jeder Art in der Nähe menschlicher Behausungen brütet. Diese Stechmücken leben in der Nähe der Häuser und werden durch Stechen eines Menschen infektiös, der sich im virämischen Stadium befindet. Das Städtegelbfieber wird in seinen Endemiegebieten durch ständige Zuwanderung empfänglicher Personen, durch Gelbfieber-Erkrankungen und durch Aedes aufrechterhalten. Durch Maßnahmen der Mückenbekämpfung wurde das Städtegelbfieber in Südamerika praktisch ausgerottet.

Dschungelgelbfieber ist in erster Linie eine Erkrankung bei Affen. In Südamerika und in Afrika wird das Virus von Affe zu Affe durch Stechmücken, die in Bäumen leben (Haemagogus, Aedes), übertragen. Die Infektion der Tiere kann sowohl inapparent als auch klinisch manifest verlaufen. Kommen Menschen, wie z.B. Holzfäller, Nüssesammler oder Straßenbauarbeiter, mit diesen Mücken im Wald in Kontakt, so können sie infiziert werden. Dschungelgelbfieber kann außerdem dann auftreten, wenn ein infizierter Affe menschliche Ansiedlungen aufsucht und durch A. aegypti gestochen wird, die dann wiederum das Virus auf den Menschen überträgt.

Das Virus vermehrt sich in den Mücken, die lebenslänglich infektiös bleiben. Nachdem die Mücke virushaltiges Blut aufgesogen hat, ist ein Intervall von 12-14 Tagen erforderlich, bis die
Tiere infektiös werden; dieses Intervall nennt man die externe Inkubationszeit.

Alle Altersgruppen sind für eine Infektion empfänglich, aber die Erkrankung bei Kindern soll milder verlaufen als bei älteren Menschen. Inapparente Infektionen sind häufig. Die Erkrankung verläuft bei Negern im allgemeinen milder als bei Menschen anderer Rassen. Über ein Vorkommen von Gelbfieber in Indien oder im Orient ist niemals berichtet worden, obwohl der Überträger, Aedes aegypti, dort weit verbreitet ist.

Neue Ausbrüche treten auch weiterhin auf. In Bolivien wurde in der ersten Jahreshälfte 1975 über 145 Fälle von Dschungel-Gelbfieber mit einer Letalität von über $50 \%$ berichtet. Die Erkrankung trat bei nicht-immunen Personen auf, die von weither zugereist waren; die meisten Erkrankungen traten in höheren Lagen nach der Reisernte auf. Diese Reisfelder liegen meist in der Nachbarschaft vom Dschungel und sind nicht weit von den Städten entfernt. Einige Erkrankungen und auch Todesfälle wurden bei empfänglichen Personen beobachtet, die den Dschungel nicht betreten, sondern nur in der Nachbarschaft gearbeitet hatten. Das Virus hat sich offenbar Reservoire in der Nähe der Stadt geschaffen. Das Dschungel-Gelbfieber befällt nur selten die ansässige Bevölkerung, die aufgrund vorausgegangener Infektionen und durchgemachter Schutzimpfungen eine Immunität erworben hat. Die meisten Erkrankungen werden bei 20-39 Jahre alten Männern beobachtet, die auch am häufigsten in der Landwirtschaft Arbeit suchen; praktisch alle Erkrankungen traten bei Ungeimpften auf. Die tatsächliche Erkrankungs- und Todeszahlen an DschungelGelbfieber liegen sehr viel höher als die berichteten, da viele Patienten keinen Arzt aufsuchen und spontan genesen oder der Erkrankung erliegen.

\section{Kontrolle}

Energische Maßnahmen zur Eindämmung der Mückenverbreitung haben das Städtegelbfieber praktisch ausgerottet. Der letzte Ausbruch von Gelbfieber in USA trat 1905 auf. Bei der Schnelligkeit des modernen Lufttransportes müssen die Gesundheitsbehörden in Gebieten, wo A. aegypti vorkommt, außerordentlich wachsam sein. Die meisten in Frage kommenden Länder bestehen auf einer ausreichenden Mückenkontrolle der Flugzeuge und der Imp- 
fung aller Personen mindestens 10 Tage vor der Ankunft in einem endemischen Gebiet oder der Abreise aus einem derartigen Endemiegebiet.

In dem 17D-Stamm steht eine ausgezeichnete, abgeschwächte Lebendvaccine zur Verfügung. Die Vaccine wird in Eiern hergestellt und dann als Trockenpulver in kleinen Ampullen in den Handel gebracht. Da es sich um eine Lebendvaccine handelt, müssen diese Ampullen kalt gelagert werden. Unmittelbar vor Gebrauch löst man den Inhalt der Ampulle auf und injiziert ihn subcutan, durch Scarifikation der Haut oder durch Hochdruck-Injektion. Die Vaccine enthält Hühnereiweiß, und aus diesem Grund müssen die Impflinge vorher über eine mögliche allergische Reaktion gegen derartiges Eiweiß befragt werden. Eine einzige Injektion führt bei über $95 \%$ der Geimpften zu einer guten Antikörperbildung. Die gute Persistenz der Antikörper hat zu einer Verlängerung der empfohlenen Fristen für Wiederimpfungen auf 10 Jahre geführt; bei den meisten Impflingen können deutliche Titer neutralisierender Antikörper auch nach noch längeren Zeiten nachgewiesen werden. Nach der Impfung vermehrt sich das Virus und kann aus dem Blut — bevor sich Antikörper entwickeln - isoliert werden. Neben der Virämie hat man auch zirkulierendes Interferon bei den Impflingen gefunden, das vielleicht die Dauer der Virämie begrenzt und eine früh einsetzende Resistenz vermittelt (s. S. 429).

Bei Tierexperimenten hat sich ein Impfschema bewährt, bei dem gegen drei Arboviren der B-Gruppe immunisiert wird: Gelbfieber (Stamm 17-D), attenuiertes Denguevirus Typ 2 und attenuiertes Langatvirus E5.

\section{Dengue}

Dengue ist eine durch Mücken übertragene Infektionskrankheit, die durch Fieber, Muskelund Gelenkschmerzen, Lymphadenopathie und Exanthem gekennzeichnet ist.

\section{Eigenschaften der Viren}

A. Größe: Der Durchmesser der Viren beträgt etwa $50 \mathrm{~nm}$ (Innenkörper $25 \mathrm{~nm}$ ).

B. Verhalten gegenüber physikalischen und chemischen Einflüssen: Die Viren sind zumindest 5 Monate lang im gefrorenen Zustand bei $-70^{\circ} \mathrm{C}$ stabil und im lyophilisierten Zustand bei $+5^{\circ} \mathrm{C}$. Menschliches Blut kann infektiös bleiben, wenn es bei $5^{\circ} \mathrm{C}$ wochenlang aufbewahrt wird.

C. Empfänglichkeit von Tieren: Menschliches Serum, das Denguevirus enthält, führt lediglich zu einer inapparenten Infektion bei Schimpansen und niederen Affen. Nach der Infektion kommt es zum Auftreten komplementbindender und neutralisierender Antikörper, die mehrere Monate lang bestehen bleiben.

Mäuse zeigen nach Inoculation virushaltigen menschlichen Serums im allgemeinen keine Krankheitssymptome. Verschiedene Virusstämme wurden jedoch an Mäuse adaptiert. Nach intracerabraler Inoculation zeigen die Mäuse schlaffe Lähmungen, wobei die histologischen Läsionen vorwiegend in den Neuronen zu suchen sind. Mäuse-adaptiertes Denguevirus kann eine tödlich verlaufende paralytische $\mathrm{Er}$ krankung bei Affen hervorrufen, die sowohl im klinischen als auch im pathologisch-anatomischen Aspekt der experimentellen Poliomyelitis ähnlich ist.

In Affennierenzellen (LLC-MK $\mathrm{MK}_{2}$ ), Hamsternieren- und HeLa-Zellen vermehrt sich Denguevirus sehr gut, wobei es cytopathische Veränderungen verursacht, die zur Titration des Virus und zur Messung neutralisierender Antikörper verwendet werden können. Außerdem eignen sich Zellkulturen von Aedes albopictus zur primären Virusisolierung.

D. Antigenität: Gegenwärtig werden zumindest vier Serotypen unterschieden, die als Typen 1-4 bezeichnet werden.

Aus den Hirnen infizierter neugeborener Mäuse können komplementbindende und hämagglutinierende Antigene hergestellt werden. Obwohl Dengue- und Gelbfiebervirus eine Gruppenverwandtschaft zeigen, findet sich zwischen ihnen keine Kreuzimmunität. Menschliche Freiwillige, die mit Gelbfiebervirus immunisiert worden waren, konnten durch kleine Dosen von Denguevirus noch infiziert werden.

\section{Pathogenese und Pathologie}

Bei Beginn des Fiebers besteht eine Virämie, die etwa 3 Tage anhalten kann. Histologische Läsionen finden sich in und um die kleinen Blutgefäße, wobei sich eine Endothelschwellung, ein perivasculäres Ödem und eine Infiltration mit mononucleären Zellen bildet. 
Die intradermale oder intraoculäre Inoculation kleiner Virusdosen kann entweder zu einer typischen Dengue-Erkrankung oder zu einer milden Erkrankung ohne Exanthem führen oder auch keinerlei Krankheitssymptome hervorrufen. In jedem Fall entsteht eine Immunität.

\section{Klinische Befunde}

Die Inkubationszeit beträgt 5-8 Tage. Das Fieber kann entweder plötzlich einsetzen oder es können Prodromalsymptome in Form von allgemeinem Krankheitsgefühl, Schüttelfrost und Kopfschmerzen vorhanden sein. Danach treten rasch Schmerzen auf, vor allem im Rükken, in den Gelenken, in den Muskeln und in den Augäpfeln. Häufig findet sich ein gerötetes Gesicht und injizierte Conjunctiven. Nach 5-6 Tagen kehrt die Temperatur wieder zur Norm zurück oder aber sie geht nach drei Tagen etwas zurück und steigt etwa 5-8 Tage nach Beginn der Erkrankung erneut an (,Sattelform“). Am 3. oder 4. Tag entsteht ein maculo-papulöses oder auch ein scarlatiniformes Exanthem, das 24 bis $72 \mathrm{Std}$ bestehen bleibt und ohne Abschuppung abklingt. Die Lymphknoten sind häufig vergrößert. Regelmäßig tritt eine Leukopenie mit relativer Lymphocytose auf. Die Rekonvaleszenz kann Wochen dauern, obwohl Komplikationen oder Todesfälle selten sind. Vor allem bei kleinen Kindern kann Dengue als milde, fieberhafte Erkrankung, die 1-3 Tage dauert, auftreten.

Ein klinisch schwereres Syndrom, das hämorrhagische Dengue-Fieber, tritt bei einigen Menschen mit heterologen Antikörpern gegen Dengue auf; diese Antikörper können entweder diaplacentar übertragen oder endogen gebildet sein. Obwohl die anfänglichen Symptome der normalen Dengue ähneln, verschlechtert sich das Befinden des Patienten anschließend abrupt, eine Hypoproteinämie und zumindest eine der folgenden hämatologischen Veränderungen machen sich bemerkbar: Thrombocytopenie, verlängerte Blutungszeit, verlängerte Prothrombinzeit. Das sog. Dengue-Schocksyndrom mit Schock und Hämokonzentration kann sich anschließen. Dieses abgewandelte klinische Bild der Dengue ist häufig in epidemisch gehäufter Form auf den Philippinen, in Südostasien und in Indien beobachtet worden, d.h. in Gebieten, in denen regelmäßig mehrere Serotypen des Denguevirus vorkommen. Die Letalität dieser Erkrankung beträgt $5-10 \%$. Bei Untersuchungen in Südostasien konnte das hämorrhagische Dengue-Fieber häufiger nach Zweitinfektion mit Denguevirus Typ 2 bei Mädchen im Alter von 3 Jahren oder älteren beobachtet werden. Die Faktoren, die zur Ausbildung des klinischen Bildes, beitragen, kennt man nicht, wahrscheinlich ist es jedoch eine Überempfindlichkeitsreaktion. Man hat angenommen, daß innerhalb weniger Tage nach der Zweitinfektion VirusAntikörperkomplexe gebildet werden, anschließend wird das Komplementsystem aktiviert und führt zu der Dysfunktion des Gefäßsystems, wie man es beim hämorrhagischen Fiebersyndrom sieht.

Die mögliche Bedeutung von Überempfindlichkeitsreaktionen bei der Auslösung des hämorrhagischen Dengue-Fiebers lassen eine $\mathrm{Zu}$ rückhaltung bei der Entwicklung von Impfstoffen gegen Dengue-Viren angezeigt sein.

\section{Laboratoriumsdiagnose}

Die Isolierung der Dengueviren ist schwierig. Bis zur endgültigen Klärung der Anwendbarkeit von Zellkulturen aus A. aegypti zur Primärisolierung können folgende diagnostische Untersuchungen durchgeführt werden:

A. Verdachtsdiagnose: Bei dieser Untersuchung wird eine Gruppe von Mäusen frisches Serum aus der akuten Krankheitsphase inoculiert, einer anderen Gruppe von Mäusen erhitztes Serum $\left(56^{\circ} \mathrm{C}, 30 \mathrm{~min}\right.$ lang). Einen Monat später führt man bei beiden Gruppen von Mäusen eine Belastungsinoculation mit 100 $\mathrm{LD}_{50}$ eines bekannten, an Mäuse adaptierten Denguevirusstammes durch. Überleben die Mäuse, die das frische Serum erhielten, diese Belastung, während jene Mäuse, denen das erhitzte Serum inoculiert wurde, sterben, so enthielt das Serum Denguevirus.

B. Serologie: Nach der Infektion bilden die Patienten neutralisierende und hämagglutinationshemmende Antikörper, die innerhalb von sieben Tagen nach Krankheitsbeginn nachweisbar sind, während die komplementbindenden Antikörper etwa 7-14 Tage später entstehen.

Zur Feststellung von Antikörpern müssen die Antigene der örtlich vorkommenden Serotypen des Denguevirus verwendet werden. Der Patient bildet zwar sowohl homotype als auch heterotype Antikörper gegen Denguevirus, jedoch kann der infizierende Typ aufgrund folgender Unterschiede bei der Antikörperbildung 
ermittelt werden: 1. Neutralisierende Antikörper: Homotype Antikörper weisen bei Erstinfektionen einen höheren Titer als heterotype auf. 2 . Komplementbindende Antikörper: Häufig sind die heterologen Antikörper niedriger und sind weniger lange nachweisbar als die homologen. 3 . Hämagglutinationshemmende Antikörper: Die homologen Antikörper können früher auftreten, einen höheren Titer besitzen und länger nachweisbar sein als die heterologen Antikörper. Ferner werden bei Erstinfektionen auch Antikörper gegen die anderen Mitglieder der Gruppe B der Arboviren gebildet.

\section{Immunität}

Man kennt zumindest vier Antigentypen des Virus.

Die Reinfektion eines Menschen, der 2 bis 3 Monate vorher durch einen anderen Typ des Denguevirus infiziert worden war, kann zu einem allgemeinen Krankheitsgefühl mit kurzdauerndem geringen Fieberanstieg führen, ohne daß ein Exanthem auftritt. Läßt man an diesem reinfizierten Patienten Mücken saugen, so können diese die Erkrankung weiter übertragen. Die höchsten Antikörpertiter bilden sich nach Infektionen mit Denguevirus Typ 1 und 2 aus. Hierbei können ausreichend kreuzragierende Antikörper gebildet werden, um eine Infektion mit den Typen 3 oder 4 zu verhindern.

Durch die Adaptierung an Mäuse und an Gewebekulturen wurden die Stämme abgeschwächt und verursachen keine Erkrankung des Menschen. Nach Injektion eines abgeschwächten Virus besitzen Menschen eine belastbare Immunität gegenüber dem homologen Virus, das durch infizierte Mücken oder auch durch die Inoculation großer Mengen hochinfektiösen menschlichen Serums übertragen wurde.

Früher gegen Gelbfieber Geimpfte zeigen eine breite anamnestische Antikörperbildung nach experimenteller Immunisierung mit abgeschwächtem Denguevirus. Dasselbe trifft für die Menschen zu, die früher durch andere Arboviren der Gruppe B infiziert worden waren.

\section{Epidemiologie}

Nach heutiger Kenntnis kommen Dengueviren in Indien, dem Fernen Osten, auf den Karibischen Inseln und auf Hawaii vor. Gelegentlich wurde Dengue auch in den Südstaaten der USA (1934) und in Australien beobachtet. Man muß wohl alle tropischen oder subtropischen Gebiete der Erde, in denen Stechmücken der Gattung Aedes als Vektor vorkommen, als Endemiegebiete oder potentielle Endemiegebiete ansehen. So traten 50000 Dengue-Erkrankungen 1972 in Kolumbien auf, nachdem das atlantische Küstengebiet erneut von A. aegypti besiedelt worden war.

Denguevirus wird lediglich durch bestimmte Species von Aedes, vor allem durch Aedes aegypti, übertragen. Der Infektionscyclus zeigt folgenden Verlauf:

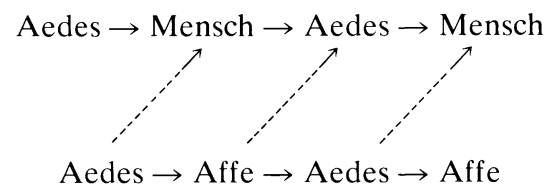

Aedes aegypti ist eine in der Nähe menschlicher Behausungen lebende Mückenart, Aedes albopictus lebt dagegen im Busch oder im Dschungel. Die letztere Mückenart hält man für das Fortdauern der Infektion unter Affen (Dschungel-Dengue) verantwortlich.

In städtischen Gebieten treten Dengue-Epidemien häufig explosionsartig auf und die Erkrankung befällt einen nicht unbeträchtlichen Teil der Gesamtbevölkerung. Die Erkrankungshäufung setzt meist während der Regenzeit ein, wenn die als Vektor dienende A. aegypti weit verbreitet ist. Diese Stechmücke ist domestiziert und besitzt nur einen engen Flugradius, so daß Dengue innerhalb der Städte sich nur von Haus zu Haus ausbreitet. Aedes brütet in tropischen und subtropischen Gebieten in künstlich angelegten Wasserlöchern in der Umgebung menschlicher Wohnungen oder aber in Löchern in Bäumen oder Pflanzen in der Nähe menschlicher Behausungen. Diese Mücke bevorzugt offensichtlich das Blut des Menschen gegenüber dem Blut von Tieren. Da A. aegypti auch der Überträger des Gelbfiebers ist, sollte der kürzlich erfolgte Dengue-Ausbruch in der Karibischen See als Warnung vor einer möglicherweise ernsteren Krankheitsepidemie angesehen werden. In diesem Gebiet traten bis 1975 sporadische Erkrankungsfälle und lokalisierte Ausbrüche auf, als wiederum eine deutliche Erkrankungshäufung auf Puerto Rico beobachtet wurde; in den folgenden Monaten wurden über 1300 Erkrankungen - vor allem in Gebiet der 
Stadt San Juan - beobachtet. Die Epidemie konnte durch Versprühen von Malathion, um die Stechmücke zu töten, und durch Vernichtung der Brutplätze der Larven rasch unter Kontrolle gebracht werden.

A. aegypti ist der einzige bekannte Überträger von Dengue in der westlichen Hemisphäre. Die weiblichen Tiere nehmen das Virus während des Saugens bei einem Menschen, der sich in der virämischen Phase befindet, auf; der Stich dieser Tiere ist dann nach etwa 8-14 Tagen (externe Inkubationszeit) infektiös. Im Durchschnitt beginnen 2-15 Tage nach dem Mückenstich die klinischen Symptome. Nachdem die Stechmücke einmal infektiös ist, bleibt sie es wahrscheinlich lebenslang ( 1 bis 3 Monate oder länger).

Anhaltspunkte für eine Übertragung des Virus von einer Generation der Mücke auf die nächste gibt es nicht. Die Erkrankung ist stets in tropischen Gebieten vorhanden, wo die Mücken während des ganzen Jahres vorhanden sind. Ausbrüche in kälteren Gebieten werden im allgemeinen durch den Beginn der kalten Jahreszeit beendet.

Dengue-Epidemien werden gewöhnlich dann beobachtet, wenn das Virus in neue Gebiete eingeschleppt wird oder wenn empfängliche Menschen in Endemiegebiete kommen. Wenn der Viruscyclus das ganze Jahr über aufrechterhalten wird, so kann die Krankheit endemisch werden, wie es im Gebiet der Karibischen See geschehen ist. Wird die Infektion dagegen in ein Gebiet mit gemäßigtem Klima eingeschleppt, wo der Zwischenwirt während des Winters verschwindet, so kommt die Epidemie dann sofort zu einem Stillstand und tritt im nächsten Jahr nicht erneut auf. Aus diesem Grund ist die endemische Dengue auf den Inseln der Karibischen See im Hinblick auf die Mücke A. aegypti, die in den Sommermonaten allgemein verbreitet ist, eine ständige Bedrohung für die USA.

\section{Kontrolle}

Die Kontrolle der Erkrankung hängt entscheidend von den Maßnahmen der Mückenbekämpfung ab, d.h. Vernichtung der Brutplätze und Verwendung von Insecticiden. Für experimentelle Zwecke wurde eine abgeschwächte Virusvaccine hergestellt, die jedoch noch nicht in einem großen Feldversuch erprobt wurde und deren allgemeine Anwendung auch so lange nicht ratsam ist, bis die mögliche Überempfindlichkeitsreaktion als auslösender Faktor für das hämorrhagische Dengue-Fieber nicht geklärt ist.

\section{Hämorrhagisches Fieber}

Krankheitsausbrüche an hämorrhagischem Fieber traten bisher in Sibirien, in den sowjetischen zentralasiatischen Gebieten, in Ost- und Nordeuropa sowie kürzlich in Südostasien und in Südamerika auf. Diese Erkrankungen gerieten in das Licht der Öffentlichkeit, als die amerikanischen Truppen in Korea im Beginn der fünfziger Jahre einen Ausbruch des koreanischen hämorrhagischen Fiebers erlebten.

Kürzlich wurde vorgeschlagen, die hämorrhagischen Fieber in drei Gruppen einzuteilen:

1. Durch Zecken übertragene hämorrhagische Fieber; hierzu gehören einige Arten des russischen Frühsommer-Meningoencephalitis-Komplexes (hämorrhagisches Fieber von Omsk, Kyasanur-Waldkrankheit) und die Gruppe des Krim-Kongo-hämorrhagischen Fiebers;

2. Durch Stechmücken übertragene hämorrhagische Fieber, hierzu gehören Dengueviren (siehe oben), das Gelbfieber- und das Chikungunya-Virus;

3. Primäre Zoonosen, hierzu gehören die Viren des koreanischen hämorrhagischen Fiebers (Nephrose-Nephritis), des argentinischen (Junin-Virus) und bolivianischen (Machupo-Virus) hämorrhagischen Fiebers und das Lassa-Virus.

In Marburg trat 1967 ein Ausbruch eines hämorrhagischen Fiebers bei Personen auf, die mit grünen Meerkatzen (Cercopithecus aethiops) Kontakt hatten; diese Tiere waren kurz zuvor aus Uganda zu Versuchszwecken importiert worden. Der Übertragungsweg dieses Virus ist unbekannt: das Virus zeigt einige wenige Gemeinsamkeiten mit den Rhabdoviren (s. Kapitel 39).

$\mathrm{Zu}$ den üblichen klinischen Symptomen der epidemisch gehäuft auftretenden hämorrhagischen Fieber gehören Fieber, Petechien oder Purpura sowie gastrointestinale Blutungen und Blutungen aus der Nase sowie dem Uterus. Ferner beobachtet man eine Hypotonie, eine allgemeine Erschöpfung, zentralnervöse Störungen und eine Thrombocytopenie. Häufig treten eine Leukopenie auf sowie eine deutliche Proteinurie. 
Das argentinische hämorrhagische Fieber wurde erstmals 1955 in der Nähe der Stadt Junin beobachtet, wo das Virus aus Patientenblut isoliert werden konnte. Von hier aus breitete sich das Virus langsam über das Land aus.

Das Machupo-Virus wurde 1963 aus der Milz eines an einem hämorrhagischen Fieber Verstorbenen in den nordöstlichen Gebieten Boliviens isoliert. Außerdem wurde dieses Virus wiederholt von der Maus Calomys calosus isoliert. Die systematische Vernichtung dieser Feldmaus gestattete, die Ausbreitung dieser Erkrankung in Bolivien zu kontrollieren.

\section{Pappatacifieber (Phlebotomusfieber)}

Pappatacifieber ist eine milde verlaufende, durch Insekten übertragene Erkrankung, die vor allem in den Mittelmeerländern und in Rußland, Iran, Pakistan, Indien, Panama, Brasilien und Trinidad auftritt. In den endemischen Gebieten zwischen dem 20. und 45. Breitengrad findet sich die Sandfliege, Phlebotomus papatasii.

\section{Eigenschaften des Virus}

Das Virus hat einen Durchmesser von etwa $50 \mathrm{~nm}$. Obwohl zumindest 20 verschiedene Antigentypen des Virus vorkommen, sind lediglich fünf als Ursache des Pappatacifiebers von Belang. Die Mitglieder dieser Gruppe sind in ihrer Antigenität von anderen Arbovirusgruppen verschieden; sie können in Gewebekulturen vermehrt werden und sind an jugendliche Mäuse und Hamster adaptiert worden, bei denen sie eine Encephalitis hervorrufen. Die Viren sind gegenüber Einfrieren und Lyophilisieren resistent.

\section{Klinische Befunde}

Beim Menschen führt der Biß der Sandfliege zu einer kleinen, juckenden Papel, die bis zu fünf Tagen bestehen bleiben kann. Wenn das Virus durch den Biß der Sandfliege eingedrungen ist, beginnt die Erkrankung abrupt nach einer Inkubationszeit von 3-6 Tagen. In einem Zeitraum von $24 \mathrm{Std}$ vor bis $24 \mathrm{Std}$ nach dem Beginn des Fiebers kann das Virus aus dem Blut isoliert werden. Die Symptome bestehen in Kopfschmerzen, allgemeinem Krankheitsgefühl, Schwindel, Fieber, conjunctivaler Injektion, Photophobie, Nackensteife, Leibschmerzen und Leukopenie. Alle Patienten erholen sich nach dieser Infektion vollständig. Eine spezifische Behandlung ist nicht bekannt. Die beim Menschen auftretenden pathologisch-anatomischen Veränderungen sind ebenfalls unbekannt.

\section{Laboratoriumsdiagnose}

Die Diagnose wird im allgemeinen nach dem klinischen Bild gestellt. Sie kann durch den Nachweis eines Antikörperanstiegs bei Untersuchung mehrerer Serumproben bestätigt werden, wobei man entweder einen Neutralisationstest mit einem Mäuse-adaptierten Virus durchführt oder einen Hämagglutinationshemmungstest, bei dem ein Hämagglutinin benutzt wird, das an das Virus gekoppelt ist.

\section{Immunität}

Die Immunität ist spezifisch für jeden Antigentyp des Virus und bleibt mindestens zwei Jahre lang bestehen.

\section{Epidemiologie}

Die Erkrankung wird durch die weibliche Phlebotomus-Mücke, die nur wenige Millimeter groß ist, übertragen. Diese sogenannte Sandfliege ist in den Tropen das ganze Jahr über verbreitet; in Gebieten mit einem kühleren Klima findet man sie nur während der warmen Jahreszeit. Es ist nicht genau bekannt, wie das Virus ïberwintert. Da jedoch häufig Virus aus männlichen Phlebotomus-Mücken isoliert wurde, die keine Blutsauger sind, muß an die Möglichkeit einer transovariellen Übertragung gedacht werden.

Die externe Inkubationszeit in der Sandfliege beträgt etwa eine Woche. Das Insekt saugt während der Nacht, während des Tages kann man die Sandfliege an dunklen Plätzen (Mauerrisse, Höhlen, Häuser, Baumstämme) finden. Wenige Tage nach dem Blutsaugen werden die Eier abgelegt, bis zur Entwicklung fertiger Insekten sind etwa fünf Wochen erforderlich. Bei heißem Wetter leben die erwachsenen Tiere nur wenige Wochen. 
In Endemiegebieten tritt die Infektion und damit auch die Immunität häufig bereits während der Kindheit auf. Kommen empfängliche Erwachsene (z.B. Militär) in diese Gebiete, so können größere Ausbrüche von Pappatacifieber unter den Neuankömmlingen auftreten, wobei diese Erkrankung dann gelegentlich als Malaria mißdeutet wird.

\section{Kontrolle}

Sandfliegen sind unmittelbar oberhalb des Bodens am meisten verbreitet. Da es sich um sehr kleine Tiere handelt, können sie die üblichen Fliegenfenster und Moskitonetze passieren. Ihre Flugstrecke kann fast $200 \mathrm{~m}$ betragen. Zur Vorbeugung von Erkrankungen in endemischen Gebieten ist eine Insektenabwehr in der Nacht unter Verwendung von Insecticiden in und um die Quartiere erforderlich.

\section{Colorado-Zeckenfieber (Bergfieber, Zeckenfieber)}

Colorado-Zeckenfieber ist eine milde verlaufende, fieberhafte Erkrankung ohne Exanthem, die durch Zecken übertragen wird.

\section{Eigenschaften des Virus}

Der Einordnung des Virus des Colorado-Zekkenfiebers, das in funktioneller Hinsicht einem Arbovirus entspricht, in die Arbovirusgruppe steht die relative Resistenz gegen Lipidlösungsmittel entgegen, ferner liegt das Virusgenom wahrscheinlich als Doppelstrang-RNS vor, so daß die Einordnung in die Familie der Reoviridae am wahrscheinlichsten ist. Nach der CapsidSymmetrie und der Säurelabilität ist es zum Genus Orbivirus (s. Kapitel 39) zu rechnen (s. S. 648).

Der Durchmesser des Virus beträgt $80 \mathrm{~nm}$ mit einem inneren Capsid von $50 \mathrm{~nm}$. Gegenüber Einfrieren und Lyophilisieren ist das Virus resistent. Das Virus ist pathogen für Hamster und Mäuse; nach intracerebraler Inoculation erkranken Mäuse mit Paresen. Der Erreger vermehrt sich ferner in Gewebekulturen menschlicher Zellen und im Hühnerembryo. Aufgrund seiner Antigenstruktur ist der Erreger des Colorado-Zeckenfiebers von allen anderen Erregern verschieden.

\section{Pathogenese und Pathologie}

Das Virus wird durch den Biß einer infizierten Zecke übertragen. Im akuten Stadium der Erkrankung kann man das Virus aus dem Blut isolieren. Die beim Menschen auftretenden pathologisch-anatomischen Veränderungen sind unbekannt.

\section{Klinische Befunde}

Die Inkubationszeit beträgt 4-6 Tage. Die Erkrankung beginnt akut mit Schüttelfrost und Muskelschmerzen. Zu den typischen Symptomen gehören Kopfschmerzen, Augenschmerzen, Muskel- und Gelenksschmerzen, Schwindel und Erbrechen. Der Temperaturverlauf ist im allgemeinen biphasisch. Nach dem ersten Abschnitt, der etwa zwei Tage dauert, kann ein relativ symptomarme Periode auftreten. Die Symptome und das Fieber erscheinen dann im allgemeinen wieder und klingen nach 3-4 weiteren Krankheitstagen ab. Die Leukocyten gehen bei der Erkrankung bis auf $2-3000 / \mathrm{mm}^{3}$ herunter. Komplikationen sind unbekannt, nur über eine tödlich endende Erkrankungen wurde berichtet.

\section{Laboratoriumsdiagnose}

Das Virus kann aus dem Blut durch intraperitoneale oder intercerebrale Inoculation saugender Mäuse oder Hamster isoliert werden. Die Virämie bei Menschen dauert zumindest zwei Wochen.

Aus den infizierten Mäusehirnen kann ein spezifisches komplementbindendes Antigen gewonnen werden. Komplementbindende und neutralisierende Antikörper werden in der zweiten Krankheitswoche gebildet und sind dann mindestens drei Jahre lang nachweisebar.

\section{Immunität}

Man kennt nur einen Antigentyp. Eine einzige Infektion ist offenbar in der Lage, eine langanhaltende Immunität zu erzeugen.

\section{Epidemiologie}

Colorado-Zeckenfieber tritt nur in den Gebieten auf, in denen die Waldzecke, Dermacentor andersoni, vorkommt, z.B. in Colorado, Oregon, Utah, Idaho, Montana und Wyoming. Nach Ausbruch einer Erkrankung läßt sich im allgemeinen retrospektiv feststellen, daß die Patien- 
ten 4-5 Tage vor Beginn der Symptome sich in einem mit Zecken befallenen Gebiet aufgehalten haben und in vielen Fällen findet man noch einzelne Zecken zu diesem Zeitpunkt an ihrem Körper. Die Anwesenheit der Zecken bleibt häufig unbemerkt, da ihr Biß schmerzlos ist. Die Erkrankung tritt vor allem bei erwachsenen Männern auf, da sie ein höheres Expositionsrisiko gegenüber den Zecken besitzen.

In der Natur gesammelte Zecken (Dermacentor andersoni) waren mit dem Virus infiziert. Diese Zecke ist ein echtes Reservoir des Erregers, da das Virus transovariell durch das erwachsene Weibchen übertragen wird. Natürliche Infektionen treten bei Nagetieren auf, die als Wirte für die unreifen Entwicklungsstadien der Zecke in Betracht kommen.

\section{Kontrolle}

Die Erkrankung läßt sich am sichersten dadurch verhindern, daß man das Betreten durch Zecken befallener Wälder vermeidet. Falls dies nicht möglich ist, wird eine entsprechende Kleidung empfohlen (hohe Stiefel usw.). In Gebieten mit Zeckenbefall sollte man Menschen regelmäßig auf etwa haftende Zecken ansehen und diese dann sobald wie möglich entfernen.

Aus Hühnerembryonen, die mit Passagevirus infiziert worden waren, hat man eine abgeschwächte Lebendvaccine entwickelt und diese in begrenzten Versuchen erprobt.

\section{Lassa-Fieber}

Die ersten gesicherten Erkrankungsfälle an Lassa-Fieber traten 1969 bei Amerikanern auf, die sich im Dorf Lassa in Nigeria aufhielten. Der Erreger ist für Menschen, die nicht in diesem Gebiet geboren wurden, extrem virulent; bei insgesamt 4 Epidemien, die in verschiedenen Gebieten Westafrikas auftraten und bei denen mehr als 1000 Erkrankungsfälle auftraten, wurden Letalitätsraten von $36-67 \%$ beobachtet. Die Übertragung kann von Mensch zu Mensch erfolgen, so daß für das Krankenpflegepersonal ein Infektionsrisiko besteht. Von 20 infizierten Personen, die im Gesundheitsdienst tätig waren, starben 9.

Bei der Erkrankung an Lassa-Fieber sind fast alle Organe beteiligt, obwohl die Symptome individuell schwanken können. Die Erkrankung ist charakterisiert durch hohes Fieber, Ulcerationen in der Mundhöhle, ein hämorrhagisches Exanthem, durch eine Pneumonie sowie durch Herz- und Nierenschäden und durch schwere Muskelschmerzen. Es treten jedoch auch gutartig verlaufende, fieberhafte Erkrankungen auf.

Das Virus kann aus dem Blut des Patienten isoliert werden; die Vermehrung erfolgt in Vero-Zellen, einer Zellinie aus Nierenzellen afrikanischer grüner Meerkatzen.

Das Lassa-Fieber-Virus ist ein Mitglied der Familie Arenaviridae. Der Erreger enthält RNS; die Partikelgröße und -struktur ist unterschiedlich (70-150 nm), auf der Partikeloberfläche findet man dicht stehende Vorstülpungen sowie im Partikelinneren Granula (20-25 nm), bei denen es sich vielleicht um Wirtszell-Ribosomen handelt. In der KBR zeigt das Virus eine Kreuzreaktion mit dem LCM-Virus und den Viren des Tacaribe-Komplexes, bei denen es sich ebenfalls um Arenaviren handelt, die in der Natur durch Nagetiere übertragen werden.

Die Übertragung des Virus scheint sowohl durch direkten Mensch-zu-Mensch-Kontakt, wie er anfänglich bei den Erkrankungsfällen in Krankenhäusern beobachtet wurde, als auch durch einen, den Mensch nicht berührenden Cyclus möglich zu sein. Während der Epidemie 1972 in Sierra Leone konnte ein derartiger Ausbreitungsweg des Erregers nachgewiesen werden. Das Virus konnte von einer afrikanischen Hausrattenart, Mastomys natalensis, isoliert werden. Eine wirksame Bekämpfung von Nagetieren kann deshalb zur Eindämmung der Erkrankung sinnvoll sein, wie es z. B. auch beim bolivianischen hämorrhagischen Fieber der Fall war.

Die einzige, gegenwärtig zur Verfügung stehende Behandlung des Lassa-Fiebers besteht in der Verabreichung von Hyperimmunserum, das entweder von Rekonvaleszenten oder von der natürlich immunen Bevölkerung dieser Gebiete gesammelt werden kann. Die Verwendung von Rekonvaleszentenseren muß allerdings mit einer gewissen Vorsicht erfolgen, da das Virus mehrere Monate lang nach der akuten Infektion im Blut persistieren kann.

\section{Rift Valley-Fieber}

Dieses Virus ist vorwiegend für Schafe und andere Haustiere pathogen. Der Mensch wird während einer solchen Zoonose bei domesti- 
zierten Tieren in Afrika nur sekundär infiziert. Eine Infektion bei Laboratoriumsarbeitern ist jedoch häufig.

Die klinischen Erscheinungen ähneln den bei Dengue beobachteten: akuter Beginn, Fieber, Erschöpfung, Schmerzen in den Gliedern und Gelenken sowie gastrointestinale Störungen. Auch die Temperaturkurve ähnelt der bei Dengue und Gelbfieber beoachteten (Satteltyp). Im allgemeinen findet man eine deutliche Leukopenie. Die Erkrankung ist nur kurzdauernd, danach kommt es zu vollständiger Wiederherstellung.

Das Virus hat einen Durchmesser von $30 \mathrm{~nm}$ und kann in einer Vielzahl von Tieren vermehrt werden, wobei jedoch die Maus als das Laboratoriumstier der Wahl anzusehen ist. Im Ablauf der Erkrankung entwickeln sich komplementbindende, neutralisierende und hämagglutinationshemmende Antikörper. Die nach einer Infektion auftretenden Antikörper bleiben offenbar jahrelang bestehen.

Die Erkrankung ist nicht unmittelbar kontagiös, sie wird durch blutsaugende Insekten, die vorwiegend in der Nacht saugen (wahrscheinlich Moskitos), übertragen. Schafe können durch eine entsprechende Unterbringung in der Nacht vor einer Infektion geschützt werden.

\section{Literatur}

Arboviruses and Human Disease. Report of a WHO scientific group. WHO Technical Report Series No. 369. World Health Organization 1967.

Bokisch, V. A., et al.: The potential pathogenic role of complement in dengue hemorrhagic shock syndrome. New Engl. J. Med. 289, 996 (1973).
Doherty, R. L.: Arthropod-borne viruses in Australia and their relation to infection and disease. Progr. med. Virol. 17, 136 (1974).

Ehrenkranz, N. J., et al.: Pandemic dengue in Caribbean countries and the southern United States: Past, present and potential problems. New Engl. J. Med. 285, 1460 (1971).

Hammon, W. M., Sather, G. E.: Arboviruses. In: Diagnostic Procedures for Viral and Rickettsial Infections, 4th Ed., p. 227-280. American Public Health Association 1969.

Henderson, B. E., Coleman, P. H.: The growing importance of the California arboviruses in the etiology of human disease. Progr. med. Virol. 13, 404 (1971).

Horzinek, M. C.: The structure of togaviruses. Progr. med. Virol. 16, 109 (1973).

Luby, J. P., Sulkin, S. E., Sanford, J. P.: The epidemiology of St. Louis encephalitis: A review. Ann. Rev. Med. 20, 329 (1969).

Monath, T. P.: Lassa fever and Marburg virus disease. WHO Chron. 28, 212 (1974).

Murphy, F. A., Harrison, A. K. Whitfield, S. G.: Bunyaviridae: Morphologic and morphogenetic similarities of Bunyamwera serologic supergroup viruses and several other arthropod-borne viruses. Intervirology 1, 297 (1973).

Porterfield, J. S., et al.: Bunyaviruses and Bunyaviridae. Intervirology, Vol. 6, Issue 1, 1976.

Reeves, W. C.: Overwintering of arboviruses. Progr. med. Virol. 17, 193 (1974).

Spence, L., Jonkers, A. H., Grant, L. S.: Arboviruses in the Caribbean islands. Progr. med. Virol. 10, 415 (1968).

Theiler, M., Downs, W. G.: The Arthropod-Borne Viruses of Vertebrates: An Account of the Rockefeller Foundation Virus Program, 1951-1970. Yale Univ. Press 1973.

Von Bonsdorff, C. H., Pettersson, F.: Surface structure of Uukuniemi virus. J. Virol. 16, 1296 (1975). 